\title{
Mating Type Idiomorphs, Heterothallism, and High Genetic Diversity in Venturia carpophila, Cause of Peach Scab
}

\author{
Clive H. Bock, ${ }^{1, \dagger}$ Carolyn A. Young, ${ }^{2}$ Minling Zhang, ${ }^{1}$ Chunxian Chen, ${ }^{1}$ Phillip M. Brannen, ${ }^{3}$ Jim Adaskaveg, ${ }^{4}$ and \\ Nikki D. Charlton ${ }^{2}$ \\ ${ }^{1}$ United States Department of Agriculture-Agricultural Research Service-Southeastern Fruit and Tree Nut Research Laboratory, Byron, \\ GA 31008 \\ 2 Noble Research Institute, LLC, 2510 Sam Noble Parkway, Ardmore, OK 73401 \\ ${ }^{3}$ Department of Plant Pathology, University of Georgia, 2105 Miller Plant Sciences Building, Athens, GA 30602 \\ ${ }^{4}$ Department of Plant Pathology and Microbiology, University of California Riverside, Riverside, CA 92521 \\ Accepted for publication 3 August 2020.
}

\begin{abstract}
Scab (caused by Venturia carpophila) is a major disease affecting peach in the eastern United States. The aims of the study were to characterize the mating-type loci in $V$. carpophila, determine whether they are in equilibrium, and assess the population genetic diversity and structure of the pathogen. The mating-type gene MAT1-1-1 was identified in isolate JP3-5 in an available genome sequence, and the MAT1-2-1 gene was PCR amplified from isolate PS1-1, thus indicating a heterothallic structure. Mating-type loci structures were consistent with those of other Venturia spp. (V. effusa and V. inaequalis): the mating-type gene is positioned between $A P N 2$ encoding a DNA lyase and a gene encoding a Pleckstrin homology domain. Primers designed to each of the mating-type genes and a reference gene TUB2 were used as a multiplex PCR to screen a population $(n=81)$ of $V$. carpophila from various locations in the eastern United States. Mating types in five of the nine populations
\end{abstract}

studied were in equilibrium. Among the 81 isolates, there were 69 multilocus genotypes. A population genetic analysis of the populations with $>10$ individuals (four populations) showed them to be genetically diverse. Linkage disequilibrium was found in five of nine populations with $\geq 4$ isolates. A discriminant analysis of principal components indicated three genetic clusters, although extensive admixture was observed. Mating-type identification in $V$. carpophila provides a basis for understanding reproductive methods of the pathogen and can be a basis for further studies of the genetics of the peach scab pathogen.

Keywords: alpha-box, ascomycete, asexual reproduction, HMG-domain, mating-type gene, MAT equilibrium, MAT locus, mycology, population biology, sexual reproduction
Scab is a major disease affecting peach trees in the eastern United States (Keitt 1917; Scherm and Brannen 2005). Fruit infection by the pathogen Venturia carpophila E. E. Fisher results in small, dark surface lesions developing on the peach skin, which leads to downgrading of the fruit quality and concomitant loss in value (Anonymous 2004). V. carpophila can infect not only the fruit but also leaves and shoots (Keitt 1917). Overwintering occurs on the previous season's shoots, and it is lesions on these shoots that produce conidia between February and June (late winter through early summer) that infect the subsequent fruit crop (Keitt 1917; Lawrence and Zehr 1982; Scherm et al. 2008). The conidia of the pathogen are predominantly splash dispersed (Lan and Scherm 2003), with most lesions developing on one plane of the fruit (Bock et al. 2011). After infection of fruit, the disease has a prolonged latent period of approximately 40+ days (Keitt 1917), suggesting that it is the earlier infections that are most likely responsible for the

†Corresponding author: C. H. Bock; clive.bock@ars.usda.gov

Funding: C. H. Bock, M. Zhang, and C. Chen are supported by the United States Department of Agriculture-Agricultural Research Service through Current Research Information System projects 6606-21220-014-00D and 6606-21000-00400D. C. A. Young and N. D. Charlton are funded through the Noble Research Institute.

C. H. Bock and C. A. Young contributed equally to this work.

*The $\boldsymbol{e}$-Xtra logo stands for "electronic extra" and indicates that supplementary materials are published online.

The author(s) declare no conflict of interest.

This article is in the public domain and not copyrightable. It may be freely reprinted with customary crediting of the source. The American Phytopathological Society, 2021. visible symptoms because peaches are harvested by July or August in the eastern United States.

In addition to peach, $V$. carpophila has been identified as the causal agent of scab on apricot and almond (Ogawa et al. 1995; Teviotdale et al. 2002). The sexual stage of the pathogen was first reported on apricot in Victoria, Australia (Fisher 1961). Pseudothecia were described on leaf litter developing toward the close of winter and, after examination and additional studies, the new species V. carpophila was named (syn. Cladosporium carpophilum (Thüm.), Fusicladium carpophilum (Thüm.) Oudem., and Fusicladosporium carpophilum (Thüm.) Partr. \& Morgan-Jones). The sexual stage of the pathogen has not been described elsewhere, despite the widespread occurrence and importance of scab in the eastern United States and other peach-, almond-, and apricotgrowing areas. Furthermore, there is no information on the characteristics of the mating types structure of the fungus, which can provide useful information on and insights into aspects of the population structure, biology, and reproduction of the fungus in areas where scab is a problem for stone fruit or nut production.

Understanding the population biology of a pathogen and the characteristics of the pathogen's reproduction can provide an informed basis for several aspects, including threats to host resistance, development of fungicide insensitivity, and phytosanitary regulation (McDonald 2015; McDonald and Linde 2002; McDonald and Mundt 2016). Based on such information, actionable disease management strategies can be developed for sustainable management of a disease. Although limited information exists on the population biology, population genetics, and reproductive strategies of $V$. carpophila, an earlier study using dominant markers (random amplified polymorphic DNAs and universally primed PCR) and a small but diverse panel of isolates from the eastern United States indicated that the pathogen was polymorphic and 
exhibited diversity (Chen et al. 2014). Subsequently, a genome of $V$. carpophila was sequenced (Chen et al. 2017) and mined for microsatellites that were screened against a diverse panel of 37 isolates of $V$. carpophila that also indicated substantial diversity (Chen et al. 2018).

In ascomycetous fungi, mating-type genes control sexual reproduction (Turgeon 1998). Fungi that require strains of opposite mating types for a compatible interaction are considered heterothallic (self-sterile), while those species able to undergo sexual reproduction when a single strain is present are termed homothallic (self-fertile, which includes its mitotic descendants). In heterothallic fungi, if a mating type is absent, sexual reproduction does not occur (Chilvers et al. 2014; Wang et al. 2016). The two mating-type genes in many ascomycetes are termed MAT1-1-1 and MAT1-2-1 (although additional genes may be present in some fungal groups), are situated at a single locus, and, depending on mating type, are named MAT1-1 and MAT1-2 (the MAT idiomorphs). The two MAT genes MAT 1-1-1 and MAT1-2-1 encode for a protein with an $\alpha$-box motif and a DNA-binding domain of the high mobility group (HMG), respectively (Pöggeler 2001; Turgeon 1998; Turgeon and Yoder 2000). Although the mating strategy (homothallism versus heterothallism) of $V$. carpophila is not known, several other Venturia spp. have been characterized as heterothallic, including $V$. effusa, $V$. inaequalis and V. pirina (Keitt and Palmitter 1937; Langford and Keitt 1942; Young et al. 2018).

Mating types are generally in equilibrium in populations of heterothallic ascomycetes where sexual reproduction is known to occur (Dale et al. 2011; Linde et al. 2002, 2003); in some cases, mating types are in equilibrium yet a sexual stage remains to be identified (Linde et al. 2009; Pearce et al. 2016), providing compelling evidence of a sexual stage in these pathogens. Conversely, it is also possible for clonality to occur in the presence of sexual reproduction in some ascomycetes (Henk et al. 2012). Indeed, the mating types of many plant-pathogenic ascomycetes have now been described (Arie et al. 1997; Groenewald et al. 2006; Linde et al. 2003; Ramirez-Prado et al. 2008; Rau et al. 2005; Waalwijk et al. 2002; Young et al. 2018; Yu et al. 2015), including the mating types of Venturia spp. V. effusa and V. inaequalis that are closely related to V. carpophila (Young et al. 2018). Although $V$. effusa has been demonstrated to have mating types in equilibrium at various spatial scales (Bock et al. 2017, 2018; Young et al. 2018), the sexual stage has only been observed in vitro (Charlton et al. 2020). $V$. inaequalis, cause of apple scab, is known to undergo regular sexual reproduction (MacHardy 1996). The apple scab pathogen has population genetic structure that is congruent with this observation, which has allowed an understanding of evolutionary relationships among discernible subpopulations of the pathogen on cultivated and more isolated, native populations of the genus Malus in Europe and Asia (Gladieux et al. 2008). Population genetic structure of $V$. effusa on pecan in the United
States similarly supports the contention of sexual recombination (Bock et al. 2017; Charlton et al. 2020; Young et al. 2018). Population genetic characteristics are a product of the reproduction (sexual versus asexual) and dispersal characteristics of a fungus.

The objectives of this study were first, to identify and characterize the mating-type loci in $V$. carpophila; second, to characterize the frequency of the two mating types among the isolates collected from the different populations; and, third, to assess the population genetic diversity and structure among these populations to determine whether there is evidence of sexual recombination occurring in the southeastern United States.

\section{MATERIALS AND METHODS}

Sample locations for isolates of $\boldsymbol{V}$. carpophila. In total, 81 isolates of $V$. carpophila were sampled from diseased peach or nectarine (both Prunus persica) fruit from orchards representing the eastern United States in Peach County, GA; Decatur County, GA; Alachua County, FL; Greene County, AL; Fayette County, KY; Berks County, PA; Oconee County, SC; Cumberland County, NJ; and Frederick County, VA (Table 1; Fig. 1). Some of these isolates were previously described by Chen et al. (2018). Nectarine orchards were sampled only in South Carolina, and were included to explore the notion that isolates of $V$. carpophila from nectarine may be different to those from peach. In some cases, peach breeding material was sampled; in other cases, samples were collected from blocks of individual cultivars. Up to eight fruit were collected arbitrarily from one to six trees in the individual orchard plantings; in one case, more than a single isolate was taken from a fruit. Different individuals collected fruit in the various orchards and the relative position and distances of fruit in trees was not recorded (they may have come from the same cluster or from different branches). Also, proximity of sample trees to one another within an orchard was not specified for the different orchards.

The pathogen was isolated following the process described by Chen et al. (2018). Briefly, conidia of V carpophila scraped from scab lesions on the fruit surface were suspended in sterile distilled water, and $0.1-\mathrm{ml}$ aliquots of the suspension spread were on the surface of antibiotic-amended water agar (WA) (amended with lactic acid at $0.50 \mathrm{ml} /$ liter, streptomycin at $0.20 \mathrm{~g} /$ liter, tetracycline at $0.05 \mathrm{~g} /$ liter, and chloramphenicol at $0.05 \mathrm{~g} / \mathrm{liter}$ ) in $9.0-\mathrm{cm}$ Petri plates. Cultures were incubated at $25^{\circ} \mathrm{C}$ for $48 \mathrm{~h}$ under fluorescent lights with a 12-h photoperiod. The agar surface was inspected under a microscope at $\times 70$ for single, germinated spores. Germinated spores were carefully excised and transferred to antibioticamended potato dextrose agar (PDA) (amended as for WA) and incubated for 3 to 5 weeks on PDA as described for the WA cultures. Isolates were identified as V. carpophila based on morphological and cultural characteristics (Fisher 1961; Keitt 1917) and comparison

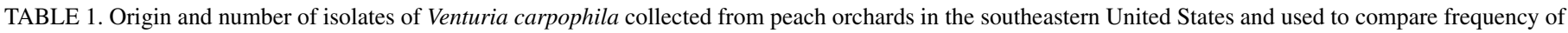
the $M A T 1-1$ and $M A T 1-2$ mating types in this study

\begin{tabular}{|c|c|c|c|c|c|}
\hline Source location (orchard population) & Host species & Cultivar or genotype (number of isolates) & $N^{\mathrm{a}}$ & Month and year of collection & Designation in study \\
\hline Peach County, GA A & Peach & Julyprince (JP) (17) & 17 & June 2013 & GA_PEA \\
\hline Peach County, GA B & Peach & APO6 (4) & 4 & May 2013 & GA_PEB \\
\hline Decatur County, GA & Peach & SIO-657-SB-654-GN14 (4), Unknown (1) & 5 & May 2013 & GA_DEC \\
\hline Alachua County, FL & Peach & $\begin{array}{l}415 X 53(3), 415 \text { XING03-1 (1), } \\
9747 \mathrm{KSBC}(2)\end{array}$ & 6 & May-June 2013 & FL_ALA \\
\hline Greene County, AL & Peach & Ruston Red (8) & 8 & July 2013 & AL_GRE \\
\hline Fayette County, KY & Peach & Unknown (1) & 1 & July 2013 & KY_FAY \\
\hline Berks County, PA & Peach & Sentry (10) & 10 & July 2013 & PA_BER \\
\hline Oconee County, SC & Nectarine & Red Gold (5) & 5 & July 2013 & $\mathrm{SC}_{-} \mathrm{OCO}$ \\
\hline Cumberland County, NJ & Peach & Encore (14) & 14 & July 2013 & NJ_CUM \\
\hline Frederick County, VA & Peach & Lovell seedling (11) & 11 & August 2013 & VA_FRE \\
\hline Total & $\ldots$ & $\ldots$ & 81 & $\ldots$ & $\ldots$ \\
\hline
\end{tabular}

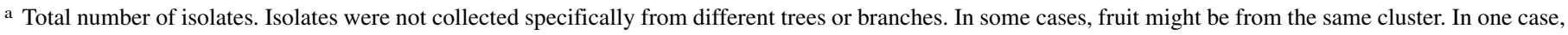
more than one isolate was obtained from a fruit. 
with previously identified cultures. All isolates are stored at $-20^{\circ} \mathrm{C}$ on silica at the United States Department of Agriculture-Agricultural Research Service, Byron, GA laboratory, with a duplicate collection similarly housed at the Noble Research Institute, Ardmore, OK laboratory.

DNA extraction. DNA was extracted from mycelium by scraping the surface of a colony growing on PDA using the QuickDNA Fungal/Bacterial Miniprep Kit (ZymoResearch, Irvine, CA, U.S.A.). ATissueLyser (Qiagen, Valencia, CA, U.S.A.) was used to lyse the mycelium. The DNA was quantified using a Nanodrop spectrophotometer (Nanodrop Products, Wilmington, DE, U.S.A.) and stored in Tris-EDTA buffer at $-20^{\circ} \mathrm{C}$. An initial set of eight isolates-one isolate from each Peach County, GA (Julyprince, isolate JP3-5), Alachua County, FL (415X53, isolate 415X53-2), Greene County, AL (Ruston Red, isolate Clanton1-2), Fayette County, KY (unknown cultivar, isolate Kent-2), Berks County, PA (Sentry, isolate PS1-1), Oconee County, SC (nectarine Red Gold, isolate MD1-3), Cumberland County, NJ (Encore, isolate RS2-2), and Frederick County, VA (Lovell seedling, isolate LO1-2) (Table 1) - was selected to evaluate the MAT locus by PCR and establish the mating-type multiplex PCR.

Genome sequence analyses. The genome from $V$. carpophila isolate JP3-5 (GenBank accession BioProject PRJNA321389) was used to identify the mating-type idiomorphs (Chen et al. 2017). The MAT1-2-1 gene and the reference $\beta$-tubulin gene (TUB2) were identified in scaffold_15 and scaffold_21 in this genome, using

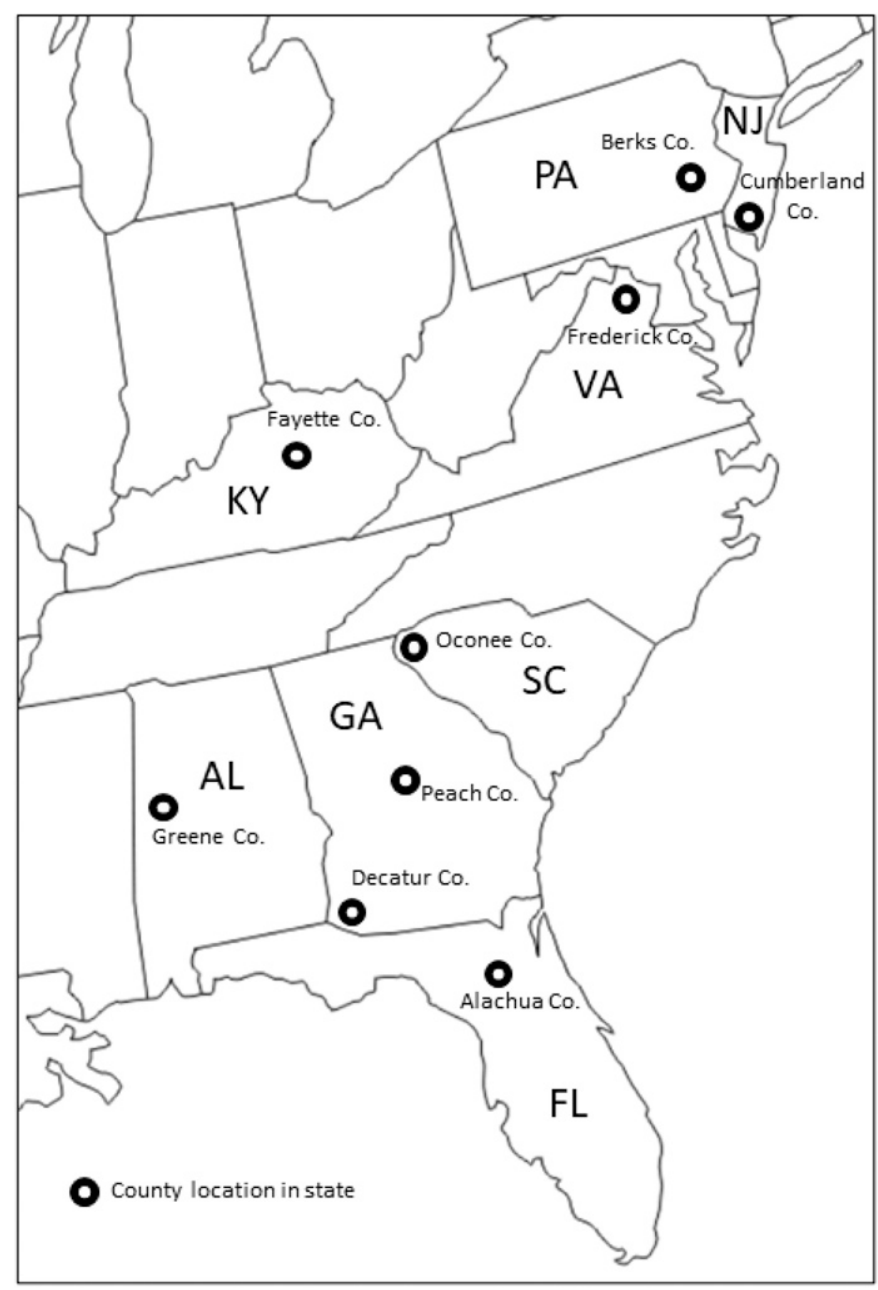

Fig. 1. States and counties within states in the eastern United States where peach orchards were located that were sampled for isolates of Venturia carpophila $. \mathrm{AL}=$ Alabama, $\mathrm{FL}=$ Florida, $\mathrm{GA}=$ Georgia, $\mathrm{KY}=$ Kentucky, $\mathrm{NJ}=$ New Jersey, $\mathrm{PA}=$ Pennsylvania, $\mathrm{SC}=$ South Carolina, and VA = Virginia.
BLAST via a custom sequence server (Priyam et al. 2019), with V. effusa sequences MF167364 and MF173107, respectively. A draft genome sequence was developed for $V$. carpophila isolate PS1-1 once it was identified as MAT1-1-1. PS1-1 was sequenced at the University of Kentucky, Health-Care Genomics Core Laboratory (Lexington, KY, U.S.A.), using Illumina MiSeq. The sequencing library was prepared using the Nextera XT DNA library kit (Illumina) producing 18,376,086 paired-end reads. The genome was assembled using SPAdes v. 3.10.1 (Bankevich et al. 2012) and all scaffold sequences at least $500 \mathrm{bp}$ in length were included in the final assembly. The final genome size was $33.3 \mathrm{Mb}$, represented by 1,762 scaffolds with an $\mathrm{N}_{50}$ of $60.1 \mathrm{~kb}$, and the largest contig was $242.8 \mathrm{~kb}$. The MAT1-1-1 and TUB2 genes were identified in scaffold_341 and scaffold_520 in the PS1-1 genome, using BLAST with V. effusa sequences MF167363 and MF173107, respectively.

Mating-type primer development. Primers designed for evaluation of the mating types by PCR are listed in Table 2. To identify and characterize the mating-type sequences of the eight selected isolates, primers (VcaMat_2F and 2R) flanking the matingtype genes were used to amplify a region that spans both matingtype idiomorphs. The PCR and conditions were the same as described below for the multiplex PCR, except the total reaction volume was $40 \mu \mathrm{l}$. PCR products were purified with the DNA Clean and Concentrator-5 (ZymoResearch) kit and sequenced using Sanger technology (University of Kentucky, Health-Care Genomics Core Laboratory).

A diagnostic multiplex PCR primer set (Table 2; Supplementary Fig. S1) was established with primers specific to each mating-type gene, used in conjunction with primers specific to TUB2, which acted as an internal positive control in all PCR assays. PCR was performed in a total volume of $5 \mu \mathrm{l}$ containing $0.75 \mu \mathrm{l}(1 \mathrm{ng})$ of genomic DNA, $2.5 \mu$ l of Promega Master Mix (Promega Corporation, Madison, WI, U.S.A.), and $0.125 \mu \mathrm{M}$ target-specific primers. The cycling parameters were $94^{\circ} \mathrm{C}$ for $1 \mathrm{~min}$; then, 32 cycles of $94^{\circ} \mathrm{C}$ for $40 \mathrm{~s}, 60^{\circ} \mathrm{C}$ for $40 \mathrm{~s}$, and $72^{\circ} \mathrm{C}$ for $20 \mathrm{~s}$; followed by $72^{\circ} \mathrm{C}$ for $10 \mathrm{~min}$. Multiplex and single-target PCR used the same reaction and cycling conditions. The PCR conditions were established using DNA from the eight selected isolates with individual primer sets and subsequently multiplexed with all three-primer sets before testing all 81 isolates. The multiplex amplicons were analyzed by gel electrophoresis using $1.5 \%$ agarose gel in $1 \times$ Tris-boric-EDTA buffer and visualized using GelRed (Biotium, Inc., Fremont, CA, U.S.A.) by UV transillumination. Amplicon size was compared against an All-Purpose Hi-Lo DNA Marker (50 to 10,000 bp; Bionexus, Oakland, CA, U.S.A.).

Analysis of the mating-type loci. Preliminary characterization of an existing genome sequence (Chen et al. 2017) facilitated the identification of the complete mating-type locus and flanking genes. The MAT1-1 and MAT1-2 loci were subsequently characterized from two isolates, PS1-1 and JP3-5, representing MAT1-1 (accession number MN562205) and MAT1-2 (accession number MN562204), respectively. Using V. effusa MF818328 (MAT1-1-1) and MF167364 (MAT1-2-1) sequences as the reference, the matingtype loci were predicted for each isolate of $V$. carpophila using the autoannotate function in Geneious v10.0.6 (Biomatters Ltd, Auckland, New Zealand) and manually annotated to correctly display features of each gene. Synteny between $V$. effusa and $V$. inaequalis against $V$. carpophila was compared using the Dot Plot function in MacVector v16.0.9 (MacVector, Inc., Apex, NC, U.S.A.) based on a window size of 30 and nucleotide identity of $60 \%$. Geneious v10.0.6 was used for generating pairwise and multiple sequence alignments of nucleotide and protein sequences using the Geneious Alignment option. The amino acid sequence for the $\alpha$ - and HMG-boxes of each mating-type gene were compared among other heterothallic ascomycete species with sequence data available on GenBank, including $V$. effusa (MF167363 and MF167364), V. inaequalis (MG818328 and MG818328), Phyllosticta citricarpa (KX280782 and KT708823), Alternaria alternata (AB009751 and AB009752), Bipolaris maydis (AF029913 and 
AF037687), Didymella tanaceti (KU030827 and KU342705), Leptosphaeria maculans (AY174048 and AY174049), Parastagonospora nodorum (AY212018 and AY212019), Dothiostroma pini (DQ915449 and DQ915451), Zymoseptoria tritici (AF440399 and AF440398), Epichloë festucae (FJ717711 and HQ680590), Neurospora crassa (NEUAMTR and NEUMTA1A), and Cryphonectria parasitica (AF380365 and AF380364).

Phylogenetic analysis of peach scab isolates using the TUB2 gene sequence. The TUB2 gene was predicted using $V$. effusa TUB2 (MF173107) sequence as the reference, using the autoannotate function in Geneious v10.0.6 and manually annotated to correctly display features of each gene. A phylogenetic tree of the partial TUB2 sequences was inferred by maximum likelihood (ML). TUB2 sequences of available Venturia spp., including unique sequences from V. carpophila isolates JP3-5, Clanton1-2, and PS11 from peach and MD1-3 from nectarine (accession numbers MN577971, MN562199, MN548432, and MN562198, respectively), were aligned with MUSCLE 3.8.1 (Edgar 2004) with Gblocks curation via the Phylogeny.fr website (http://www.phylogeny.fr). ML analyses were performed with PhyML 3.1/3.0 (Guindon et al. 2010), with branch support estimated by the approximate likelihood-ratio test; the likelihood substitution model was HKY85 with a likelihood value of -ln L 1365.66 (Dereeper et al. 2008, 2010).

Genotyping of isolates. All 81 isolates of $V$. carpophila were individually genotyped using 16 microsatellite markers (Table 3) (Chen et al. 2018). The primers and conditions used for the reactions were as follows. The reaction volume $(5 \mu \mathrm{l})$ contained $1.5 \mu \mathrm{l}$ of template DNA (1.5 to $2.0 \mathrm{ng}$ ), $0.5 \mu \mathrm{M}$ each primer, $0.75 \mu \mathrm{l}$ of distilled $\mathrm{H}_{2} \mathrm{O}$, and $2.5 \mu \mathrm{l}$ of PCR master mix (Promega Corporation). The cycling parameters were $94^{\circ} \mathrm{C}$ for $3 \mathrm{~min}$; followed by 10 cycles of denaturation at $94^{\circ} \mathrm{C}$ for $30 \mathrm{~s}$, a primer extension at $60^{\circ} \mathrm{C}$ for $45 \mathrm{~s}$ (with a $-0.5^{\circ} \mathrm{C} \mathrm{ramp} /$ cycle), and a final extension step at $72^{\circ} \mathrm{C}$ for $30 \mathrm{~s}$; and a further 29 cycles of denaturation at $94^{\circ} \mathrm{C}$ for $30 \mathrm{~s}$, a primer extension at $55^{\circ} \mathrm{C}$ for $45 \mathrm{~s}$, and a final extension step at $72^{\circ} \mathrm{C}$ for $30 \mathrm{~s}$; ending with a final extension of $72^{\circ} \mathrm{C}$ for $30 \mathrm{~min}$. Primers were labeled with either FAM, NED, HEX, or PET dye (all with M13 tails). All marker primer combinations were run on a Hitachi 3500 Genetic Analyzer (Thermo-Fisher Scientific, Grand Island, NY, U.S.A.). The resulting peaks were analyzed and scored by base pair size for each marker using GeneMarker (SoftGenetics, State College, PA, U.S.A.). $V$. carpophila is a haploid organism and, thus, only a single band was observed at each locus for each isolate. To ensure repeatability of the PCR assays, $25 \%$ of the reactions were repeated and all resulted in identical marker patterns for the marker-isolate combinations tested.

Data analysis. Analysis of mating-type frequencies. Matingtype frequencies were calculated for isolates from each orchard sample. Additionally, the isolates were pooled into a single overall population to determine whether isolates of each mating type were in equilibrium. The analyses were performed on both the original data and a clone-corrected data set. Clone correction was performed based on the haploid multilocus genotypes (MLGs) identified by combining the alleles for each microsatellite. Analyses were performed using SAS V9.4 (SAS Institute, Cary, NC, U.S.A.). The proportion of MAT1-1 and MAT1-2 isolates present was tested for equilibrium (the null hypothesis of a 1:1 ratio) using an exact

TABLE 2. Primers used in PCR to detect the mating-type idiomorph loci MAT1-1 and MAT1-2 in isolates of Venturia carpophila collected from peach orchards in the southeastern United States

\begin{tabular}{|c|c|c|c|}
\hline Target gene & Primer name & Sequence $\left(5^{\prime}-3^{\prime}\right)$ & Product size $(b p)$ \\
\hline \multirow[t]{2}{*}{$M A T 1-1-1^{\mathrm{a}}$} & VcaMat_2F & GTGTCCACGGCTCCTACAAA & 2,204 \\
\hline & VcaMat_2R & AGGCATACACATGGTCGCAA & $\ldots$ \\
\hline MAT1-1-1 b & VcaMat_8F & TGGATCCATCCTTCATCCTC & 212 \\
\hline \multirow[t]{2}{*}{$M A T 1-2-1^{\mathrm{b}}$} & VcaMat_5F & ATGTCTTCCCCAACTTCCGCAGCT & 585 \\
\hline & VcaMat_5R & AATAGTCCGGGTGCTGCAGCAAGT & \\
\hline \multirow{2}{*}{$T U B 2^{c}$} & Vcatub_F2 & CAGATATCGTACAAAGCCTCGTTG & 380 \\
\hline & Vcatub_R2 & TTCCGTCCAGATAACTTCGTCTTC & \\
\hline
\end{tabular}

a Primers used to amplify complete MAT1-1-1 and MAT1-2-1 genes.

b Primers used for multiplex PCR to differentiate isolate mating type.

c Housekeeping gene primer set used to confirm PCR in multiplex PCR.

d Primer set used for TUB2 phylogeny.

TABLE 3. Microsatellite markers used for assessing population genetic diversity of Venturia carpophila

\begin{tabular}{|c|c|c|c|c|}
\hline Primer name ${ }^{b}$ & Scaffold & Forward primer sequence & Reverse primer sequence & Product size range (bp) \\
\hline Vc007 & 2 & ACGTTATGAGCAGTAGGTAGGGAG & AGGAAGTCGGTCATGAGAAAGAAC & $280-296$ \\
\hline Vc012 & 3 & AAAGATATTGGGTTCACATGCTCT & AAAAGTGAGAGATGGAAGGATGAG & 289-319 \\
\hline Vc021 & 6 & GTAAGAAGCCTTACCCACTGTCTT & GCTTGAAGAATAGCAGTGTTGTGT & $241-260$ \\
\hline Vc046 & 21 & TTATTCTTTATAGCTAGCCGTCCG & AGTGATTGATTCCATTCTTGTTGA & $242-255$ \\
\hline Vc055 & 33 & ATAGAGGCTTATTCCTTTCCATCC & TCAAAATGTCCСТTTTCCTTTATC & $295-498$ \\
\hline Vc056 & 33 & CAATCTCTACTACGATGACGGCT & AACAGTAGCTTAGTTGTCCCTTGG & $290-317$ \\
\hline Vc060 & 35 & ACGTTCGTAATAATAGGGAGCGTA & AACCTACGAAGGTACGAGTTTACC & $257-450$ \\
\hline Vc089 & 61 & GTATCCTTTCTCTTCACCAATGCT & ACTTGAGAGTTCCTTGCTTCTTGT & 293-300 \\
\hline Vc097 & 90 & CATGATATTCTTGTCTGCGATACC & AGAACTTTCTGTCCCTGCTCTTC & $308-316$ \\
\hline Vc098 & 92 & GCGTATTTCGTAAATGCTCTATCC & TTTCAAGTTGTTTATGAGTGCAGA & $281-306$ \\
\hline Vc109 & 116 & GTTATACCCAGATGGAATCCAGAC & GAAGAGAATGGAGGACAAGGG & $270-276$ \\
\hline Vc113 & 119 & AGTAAGAGCTGGGTGGTGTGAT & CCTTCGTTTCTGACCTACCATTAT & $128-132$ \\
\hline Vc118 & 124 & ATCGTTTTTCAGATCGGGGT & AATCCAAGTACCAAACCACCTAAA & 296-308 \\
\hline
\end{tabular}

${ }^{a}$ These microsatellites were previously demonstrated to be polymorphic and reliable (Chen et al. 2018).

${ }^{b}$ Each primer name is designated with the species two-letter initials and a serial number. 
binomial test (two-tailed) for goodness-of-fit to determine whether observed mating-type frequency deviated from the 1:1 ratio.

Analysis of loci. Locus-based statistics were explored for the 16 microsatellite markers used. Most analyses were performed using $\mathrm{R}$ V3.5.0 (R Core Team 2018) and the package poppr (Kamvar et al. 2014). The data sets were checked for missing data and were coded accordingly as missing values in the analyses. Number of alleles per locus and effective number of alleles per locus were calculated. The polymorphic information content (PIC) value (Botstein et al. 1980) was calculated for each of the selected microsatellite markers as
$\mathrm{PIC}=1-\Sigma(P i) 2$ (where $P i$ is the proportion of samples carrying the $i$ th allele of a particular locus). Shannon's information index $(\mathrm{H})$ for each locus based on the marker frequency data was calculated (Shannon and Weaver 1949), and Nei's unbiased gene diversity $\left(\mathrm{H}_{\text {exp }}\right)$ was calculated for each locus (Nei 1978).

Analysis of population genetic data. Four populations with sufficient sample sizes ( $\geq 10$ individuals, which included Berks County, PA, Frederick County, VA, Peach County B, GA, and Cummings County, NJ) were included in a rarefaction analysis. For these four populations, genotypic and gene diversity was analyzed
A

MAT1-1

Venturia carpophila isolate PS1-1

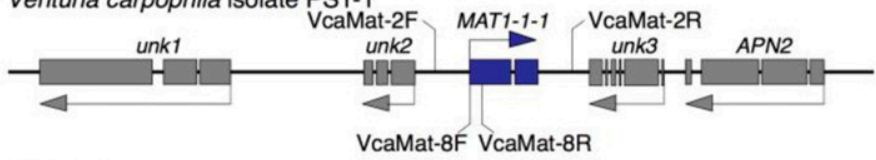

MAT1-2

Venturia carpophila isolate JP3-5

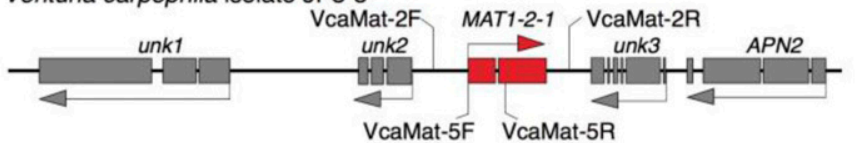

C

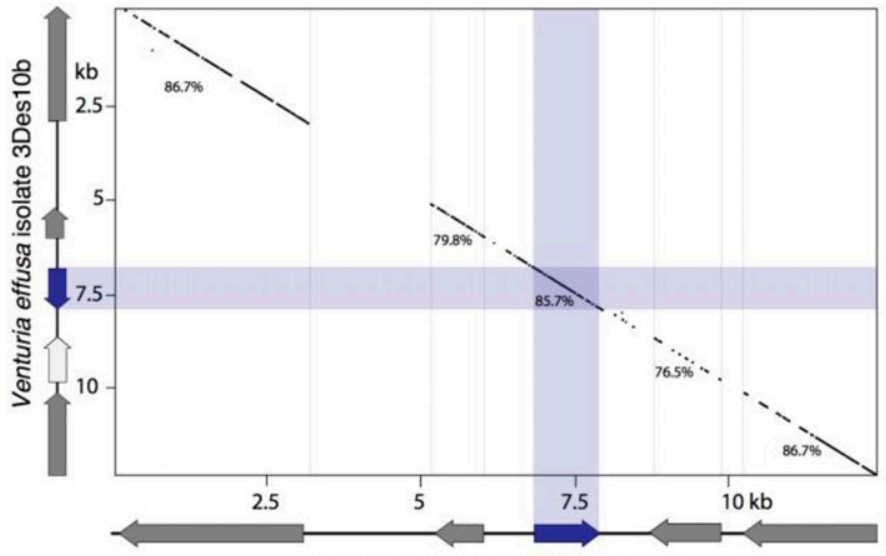

E

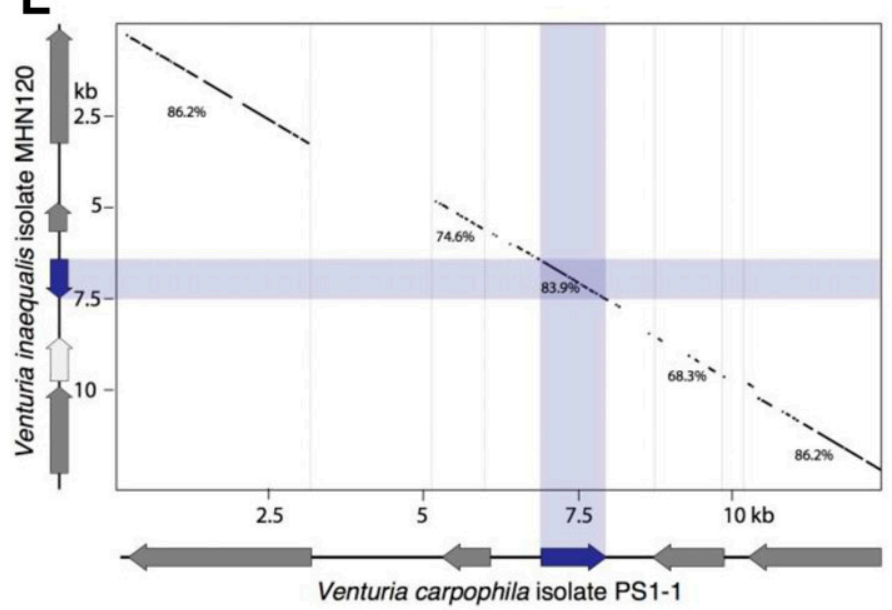

B

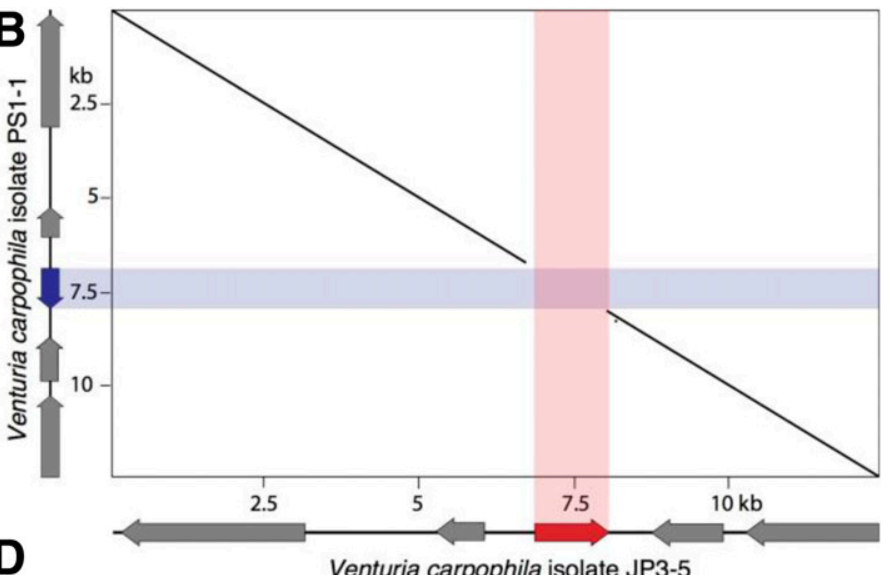

Venturia carpophila isolate JP3-5

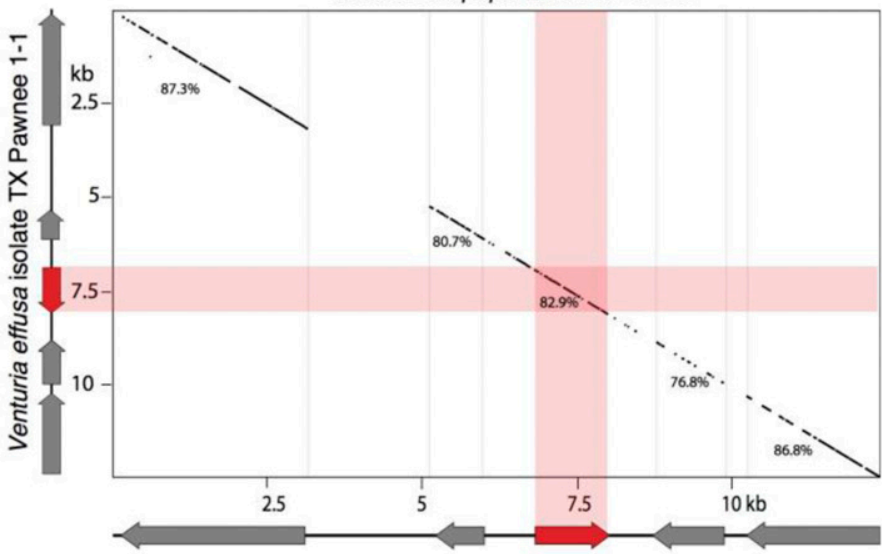

$\mathbf{F}$

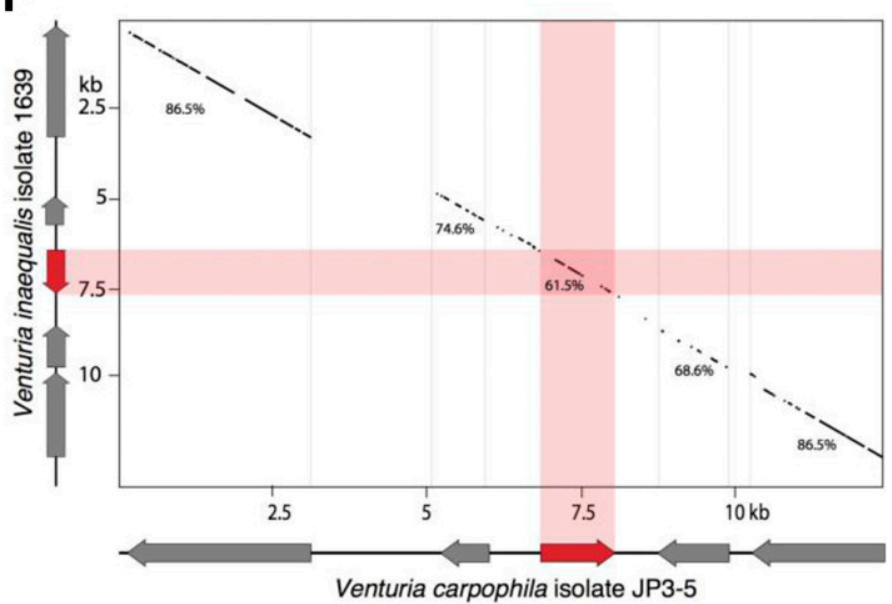

Fig. 2. Organization of Venturia carpophila mating-type genes and synteny between Venturia mating-type loci. A, Mating-type idiomorphs from V. carpophila isolate PS1-1 MAT1-1 and isolate JB3-5 MAT1-2. Each gene is represented by an arrow showing the direction of transcription over boxes that represent exons of the coding sequence. Primer locations are indicated with lines with primer names above or below the sequence line. Locus structure is compared with that of two closely related species, V. effusa and V. inaequalis. Synteny comparison of Venturia mating-type loci: B, V. carpophila MAT1-1 and MAT1-2 loci; C, V. carpophila and V. effusa MAT1-1; D, V. carpophila and V. effusa MAT1-2; E, V. carpophila and V. inaequalis MAT1-1; and F, V. carpophila and V. inaequalis MAT1-2. Dot plots show conserved regions based on a window size of 30 nucleotides with $60 \%$ identity. Percent similarity of the encoded proteins are indicated at the gene transects in panels B to F. 
for the original data and for the clone-corrected data (clone correction was performed at the appropriate level in the population hierarchy for the analysis). Analyses were based on the haploid MLGs and microsatellite allele presence and frequency, as described previously (Bock et al. 2017), and followed recommended approaches (Grünwald et al. 2017). Analyses were performed using R V3.5.0 packages poppr and adgenet (Jombert et al. 2018). The number of MLGs observed and the clone-corrected number of MLGs were calculated; the genotypic diversity, which measures both genotypic richness and abundance, was measured using the Shannon-Wiener index of MLG diversity (H) (Shannon 2001), Stoddart and Taylor's index of MLG diversity (G) (Stoddart and Taylor 1988), and Simpson's index $(\lambda)$ (Simpson 1949). Genotype evenness was measured as E0.5 (Grünwald et al. 2003; Ludwig and Reynolds 1988; Pielou 1975), and Nei's unbiased gene diversity was calculated $\left(\mathrm{H}_{\mathrm{exp}}\right)$ (Nei 1978). For all populations, the number of private alleles was calculated. For the nine populations with $\geq 4$ individuals, linkage disequilibrium was assessed using the index of association $\left(I_{A}\right)$ (Brown et al. 1980; Smith et al. 1993) and the standardized index of association $\left(\bar{r}_{d}\right)$ (Agapow and Burt 2001). Significance of $I_{A}$ and $\bar{r}_{d}$ was tested by its deviation from the expected value (zero) based on 1,000 randomizations.

For the four populations (Peach County B, GA; Green County, AL; Cumberland County, NJ; and Frederick County, VA) where there were sufficient numbers of isolates $(n \geq 10)$, further analyses of population genetic diversity and structure were conducted. An analysis of molecular variance (AMOVA) was performed on both the original and clone-corrected data. To test whether there were differences between populations, 1,000 randomizations were calculated based on the sample matrices, with no population differentiation assumed if the observed $\phi$ (the population differentiation statistic) value fell within the distribution expected from the randomizations. A discriminant analysis of principal components (DAPC) was performed on the clonecorrected data. The appropriate number of clusters (K) for the DAPC was also identified based on the Bayesian information criterion in adgenet. A minimum-spanning tree based on the (squared) distances between populations was calculated to indicate actual proximities between populations. Finally, to optimize the DAPC, the a-score was calculated, which is the difference between the proportion of successful reassignments of the analysis (observed discrimination) and values obtained using random groups (random discrimination). Based on the analysis, membership probabilities were calculated to describe the admixture within the isolates. A minimum-spanning network (MSN) was calculated for the original data from the same four populations using Bruvo's distance.

Genotypic, gene diversity, and genetic diversity and structure were also analyzed based on mating type. Thus, the numbers of isolates of MAT1-1 and MAT1-2 were presented and clone corrected to provide number of MLGs. The Shannon-Wiener index, Stoddart and Taylor's index, Simpson's index, genotype evenness, Nei's unbiased gene diversity, and number of private alleles were calculated for both the original data and the clone-corrected data, as described previously for the population data. Also as described above, linkage disequilibrium was assessed using $I_{A}$ and $\bar{r}_{d}$. To explore any structure associated with mating type, AMOVA was performed, and DAPC and MSN analyses were performed as described for the orchard population level data, except analyses were based on mating type.

\section{RESULTS}

Identification and structural arrangement of the $M A T$ loci. The mating type of $V$. carpophila isolate JP3-5 was identified as MAT1-2 using BLAST with the $V$. effusa mating-type genes against the available genome sequence (Fig. 2A). PCR performed on a subset of isolates with the VcaMat_5F/5R primer set specific for the MAT1-2-1 gene identified three isolates (JP3-5, MD1-2, and Clanton1-2) of the eight screened that amplified, which suggested that the remaining five were of the opposite mating type. The mating-type genes were sequenced from PCR products of five MAT1-1 isolates (415X53-2, Kent-2, LO1-2, PS1-1, and RS2-2) and three MAT1-2 isolates (JP3-5, MD1-2, and Clanton1-2) amplified with primers (VcaMat_2F and -2R) designed to conserved regions flanking both mating-type genes. The complete matingtype locus from isolate PS1-1 (accession number MN562205) was later made available from a genome sequence. Each mating-type gene was flanked by two previously identified genes, APN2 encoding a DNA lyase and a gene with similarity to genes encoding a protein with a Pleckstrin homology domain. Synteny between the mating-type loci from V. carpophila, V. effusa, and V. inaequalis using the Dot Plot function in MacVector revealed sequence homology $>60 \%$ of the two putative genes unk2 and unk3 (Fig. 2B to F). BLASTx analyses with the unknown gene sequences identified sequence similarity to unk3 in some other ascomycetes, whereas unk2 appears unique to Venturia spp. and was annotated with unknown function in $V$. inaequalis and $V$. nashicola genomes. The putative function of the genes encoded by unk1, unk2, and unk3 remain unknown, as well as whether a putative role is associated with mating in these fungi.

Comparison of the mating-type genes to other species and a phylogeny based on the $T \boldsymbol{T} \boldsymbol{B} 2$ gene. The $V$. carpophila isolate PS1-1 MAT1-1-1 gene is 1,069 bases in length, encoding a predicted protein of 335 amino acids. The single intron of 61 bases
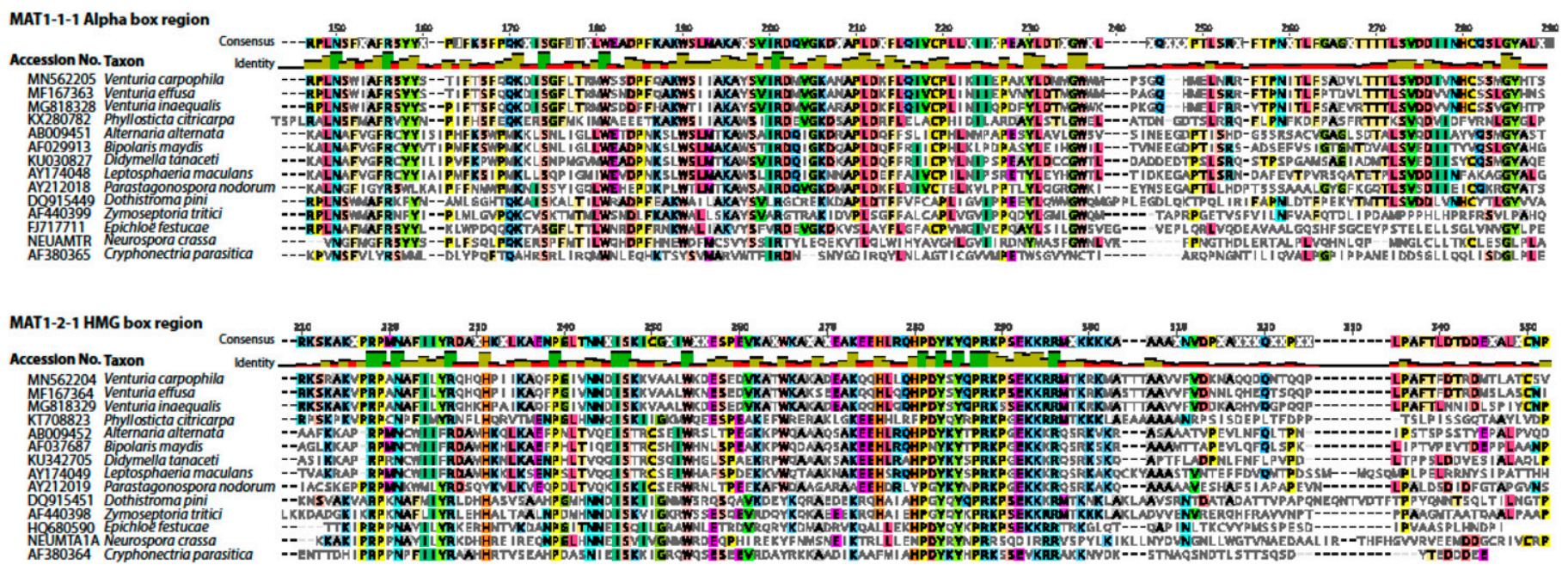

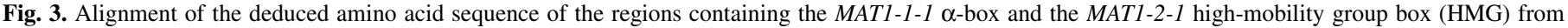
Venturia carpophila compared with those from other heterothallic ascomycetes species. Sequence accession numbers from GenBank are indicated. 
was not associated with the $\alpha$-box region. No sequence variation was observed within the five sequenced MAT1-1-1 genes from isolates 415X53-2, Kent-2, LO1-2, PS1-1, and RS2-2. The V. carpophila isolate JP3-5 MAT1-2-1 gene was 1,211 bases in length, encoding a predicted protein of 386 amino acids. The single intron of 50 bases was found within the HMG-box region with conserved placement across Venturia and other Dothideomycete species. The MAT1-2-1 gene from MD1-2, a nectarine isolate, had five single-nucleotide differences resulting in three nonsynonymous amino acid changes when compared with the gene sequences from isolates JP3-5 and Clanton1-2. The structure of MAT1-1-1 and MAT1-2-1 confirmed the presence of the $\alpha$ - and HMG-box,

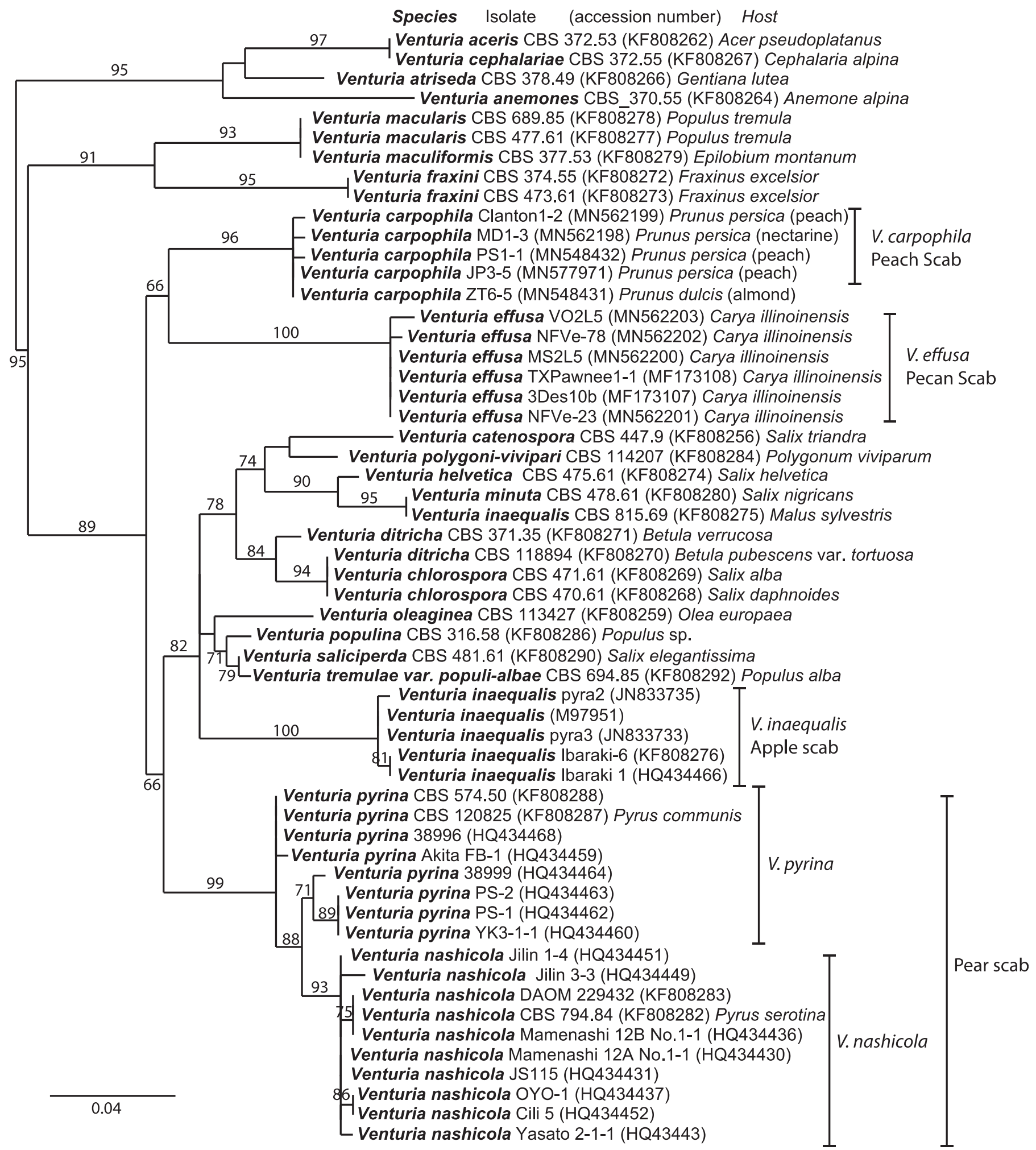

Fig. 4. Phylogenetic tree based on the partial $\beta$-tubulin gene sequences of representative Venturia spp. Numbers on branches indicate approximate likelihood-ratio test (maximum likelihood) support where they are $>50 \%$. The likelihood substitution model was HKY85 with a likelihood value of $-\ln \mathrm{L} 1365.66$. Species is followed by isolate (accession number) and, where known, the host. Isolates from peach, nectarine, and almond all cluster in a single, well-supported clade, Venturia carpophila. 
respectively, as described for several other closely related ascomycetes (Fig. 3). The alignments show close similarity between $V$. carpophila, V. effusa, and V. inaequalis amino acid sequences within the region of the $\alpha$ - and HMG-boxes but showed greatest identity to $V$. effusa (85.7 and $82.9 \%$ identity to MAT1-1-1 and MAT1-2-1, respectively), followed by $V$. inaequalis (83.3 and $69.5 \%$ identity to MAT1-1-1 and MAT1-2-1, respectively).

The TUB2 gene was identified from the sequenced genome of isolate JP3-5 and was successfully amplified using primers Vctub2$\mathrm{F}$ and Vctub2-R1 from the eight selected isolates. Phylogenetic analysis of TUB2 based on maximum likelihood separated the isolates of $V$. carpophila from peach, nectarine, and almond into a single well-supported clade (96\%), most closely related to V. effusa (Fig. 4). The TUB2 sequences for V. carpophila isolates $415 \mathrm{X} 53-2$, Kent-2, and RS2-2 were identical to JP3-5, and LO1-2 was identical to Clanton1-2. These identical sequences were not included in the phylogeny.
Genetic diversity and structure. Missing data were minimal and, thus, not a hindrance to analysis. Overall, there was $0.23 \%$ missing data (with a maximum of $16.7 \%$ at one locus-isolate combination). Depending on the locus, there were two to eight alleles among the 81 isolates sampled (Supplementary Table S1). The loci were all informative (PIC value $\geq 0.44$ ) and all had an effective allele number $>1.79$. Similarly, measures of allele diversity (Simpson's index, 0.44 to $0.79 ; \mathrm{H}_{\exp }, 0.44$ to 0.80 ) demonstrated all loci to be informative. Thus, all 16 microsatellites were retained for the population genetic analyses. Specific allele frequencies varied substantially among populations (Supplementary Table S2). Some rare alleles were absent in most populations or only present at relatively low frequency. Frequencies of specific alleles in the population of $V$. carpophila from nectarine (Oconee County, SC) was comparable with other populations from peach. Considering all 16 loci, clone correction had only a marginal effect on the Simpson's index $(\leq 0.035)$ (Supplementary Fig. S2).

TABLE 4. Statistics summarizing the genetic diversity (genotypic and gene) within nine populations of Venturia carpophila ${ }^{\text {a }}$

\begin{tabular}{|c|c|c|c|c|c|c|c|c|c|}
\hline Analysis, population ${ }^{b}$ & $N^{\mathrm{c}}$ & $\mathrm{MLG}^{\mathrm{d}}$ & eMLG $(\mathrm{SE})^{\mathrm{e}}$ & Clonal fraction & $\mathrm{H}^{\mathrm{f}}$ & $\mathrm{G}^{\mathrm{g}}$ & $\lambda^{\mathrm{h}}$ & E. $5^{\mathrm{i}}$ & $\mathrm{H}_{\exp }^{\mathrm{j}}$ \\
\hline \multicolumn{10}{|l|}{ Original data } \\
\hline PA_BER & 10 & 9 & $9.00(0.000)$ & 0.10 & 2.16 & 8.33 & 0.880 & 0.952 & 0.542 \\
\hline VA_FRE & 11 & 10 & $9.18(0.386)$ & 0.09 & 2.27 & 9.31 & 0.893 & 0.955 & 0.528 \\
\hline GA_PEB & 17 & 15 & $9.34(0.633)$ & 0.12 & 2.67 & 13.76 & 0.927 & 0.949 & 0.489 \\
\hline NJ_CUM & 14 & 9 & $7.36(0.788)$ & 0.36 & 2.11 & 7.54 & 0.867 & 0.906 & 0.442 \\
\hline \multicolumn{10}{|l|}{ Clone-corrected data } \\
\hline PA_BER & 9 & 9 & - & - & 2.20 & 9 & 0.889 & - & 0.569 \\
\hline VA_FRE & 10 & 10 & - & - & 2.30 & 10 & 0.900 & - & 0.553 \\
\hline GA_PEB & 15 & 15 & - & - & 2.71 & 15 & 0.933 & - & 0.496 \\
\hline NJ_CUM & 9 & 9 & - & - & 2.20 & 9 & 0.889 & - & 0.479 \\
\hline
\end{tabular}

${ }^{a}$ Both original and clone-corrected data are presented. Analyses were performed using poppr (Kamvar et al. 2014); - indicates that result was meaningless for clone-corrected data.

b Population: PA_BER = Berks County, PA; VA_FRE = Frederick County, VA; GA_PEB = Peach County B, GA; and NJ_CUM = Cummings County, NJ.

c Number of individuals in the population.

d Number of multilocus genotypes (MLGs) in that population.

e eMLG is an approximation of the number of genotypes that would be expected at the smallest, shared sample size. Standard error (SE) based on eMLG is shown in parentheses.

f Shannon-Wiener index of MLG diversity (Shannon 2001).

g Stoddart and Taylor's measure of genotypic diversity (Stoddart and Taylor 1988).

h Simpson's index $(\lambda)$, which is one minus the sum of squared genotype frequencies (Simpson 1949). The index provides an estimation of the probability that two randomly selected genotypes are different (from $0=$ no genotypes are different to $1=$ all genotypes are different).

i Evenness $(E .5)$ is a measure of the distribution of genotype abundances. In a population with equally abundant genotypes $E .5=1$ and a population dominated by a single genotype $E .5=$ approximately 0 (thus, for clone-corrected population, $E .5=0$ ) (Grünwald et al. 2003). For the clone-corrected data, $E .5=1.0$ for all populations.

j Nei's unbiased estimate of average heterozygosity (or gene diversity) (Nei 1978).

TABLE 5. Measures of random mating among populations of Venturia carpophila from 10 peach orchards in the eastern United States

\begin{tabular}{|c|c|c|c|c|c|c|}
\hline \multirow[b]{2}{*}{ Population $^{\text {b }}$} & \multirow[b]{2}{*}{$N(\mathrm{MLG})^{\mathrm{c}}$} & \multirow[b]{2}{*}{ Alleles $^{\mathrm{d}}$} & \multicolumn{2}{|c|}{ Original data $^{\mathrm{a}}$} & \multicolumn{2}{|c|}{ Clone-corrected data ${ }^{a}$} \\
\hline & & & $I_{A}(P$ value $)$ & $\bar{r}_{d}(P$ value $)$ & $I_{A}(P$ value $)$ & $\bar{r}_{d}(P$ value $)$ \\
\hline GA_PEA & $4(4)$ & 1 & $0.907(0.109)$ & $0.091(0.109)$ & $0.907(0.117)$ & $0.091(0.117)$ \\
\hline FL_ALA & $6(6)$ & 0 & $3.752(0.001)$ & $0.315(0.001)$ & $3.752(0.001)$ & $0.315(0.001)$ \\
\hline AL_GRE & $8(7)$ & 2 & $2.451(0.001)$ & $0.165(0.001)$ & $1.051(0.006)$ & $0.071(0.006)$ \\
\hline PA_BER & $10(9)$ & 5 & $1.809(0.001)$ & $0.121(0.001)$ & $1.597(0.001)$ & $0.107(0.001)$ \\
\hline SC_OCO & $5(5)$ & 1 & $-0.273(0.729)$ & $-0.02(0.729)$ & $-0.273(0.724)$ & $-0.02(0.724)$ \\
\hline NJ_CUM & $14(9)$ & 2 & $2.839(0.001)$ & $0.191(0.001)$ & $1.577(0.002)$ & $0.106(0.002)$ \\
\hline KY_FAY & $1(1)$ & 0 & NS & NS & NS & NS \\
\hline
\end{tabular}

a Gametic disequilibrium was measured using the index of association $\left(I_{A}\right)$ and the standardized index of association $\left(\bar{r}_{d}\right) . I_{A}$ is a measure of linkage disequilibrium. The $\bar{r}_{d}$ is a more robust measure, less sensitive to the number of loci (Agapow and Burt 2001; Brown et al. 1980; Smith et al. 1993). Statistics were calculated based on 1,000 randomizations for both the original data and the clone-corrected data. Analyses were performed using poppr (Kamvar et al. 2014). Data in bold indicate populations with loci that deviate significantly from random recombination.

b Population: GA_PEA = Peach County A, GA; FL_ALA = Alachua County, FL; GA_DEC = Decatur County, GA; AL_GRE = Greene County, AL; PA_BER = Berks County, PA; SC_OCO = Oconee County, SC; VA_FRE = Frederick County, VA; GA_PEB = Peach County B, GA; NJ_CUM = Cummings County, GA; and KY_FAY = Fayette County, KY.

${ }^{c} N=$ number of individuals and multilocus genotypes (MLG).

${ }^{\mathrm{d}}$ Number of private alleles. A private allele is one unique to that population. There were 73 alleles among the 16 loci over all 81 isolates sampled.

e Only one isolate was sampled from the Kentucky population. Thus, no statistics (NS) could be calculated. 
Four populations with sufficient sample sizes ( $n \geq 10$ individuals, which included Berks County, PA; Frederick County, VA; Peach County B, GA; and Cummings County, NJ) were included in the rarefaction analysis and, at the smallest shared sample size of 10 , the populations had similar numbers of MLGs, although the population from Cummings County, NJ tended to have fewer MLGs compared with the other three populations (Supplementary Fig. S3). The population genetic analysis of the isolates from the four different orchards from the eastern United States showed them to be a genetically diverse group (Table 4). There were 43 MLGs. Clone correction did not greatly alter the different measures of diversity, which consistently indicated substantial genotypic and gene diversity. Thus, for the clone-corrected data, the Shannon-Weiner index of MLG diversity ranged from 2.20 to 2.71, depending on population. Nei's unbiased measure of gene diversity ranged from 0.479 to 0.569 , depending on population. Even the nonclonecorrected data set showed unique MLGs to be abundant in all populations with $\geq 10$ isolates sampled ( $E .5$ was 0.906 to 0.955 , depending on population). Despite the presence of some clones in some populations (particularly the Cummings County, NJ population), the MLGs were distributed fairly evenly among the four populations with $\geq 10$ isolates of $V$. carpophila (Supplementary Fig. S4). Across all nine populations, there was an association between measures of genotypic diversity but not gene diversity and the sample size in a population (Supplementary Table S3). Associations were stronger based on MLGs (i.e., clone-corrected data). The population of $V$. carpophila from nectarine (Oconee County, SC) had genotypic and gene diversity similar to that of other populations

TABLE 6. Hierarchical analysis of molecular variance (AMOVA) of the population structure of Venturia carpophila collected from peach fruit in four different orchards in the eastern United States based on both original and clone-corrected data ${ }^{\mathrm{a}}$

\begin{tabular}{|c|c|c|c|c|c|c|}
\hline Analysis, source & df & Sum of squares & Mean squares & $\sigma$ & Variation $(\%)$ & $\phi(P$ value $)$ \\
\hline \multicolumn{7}{|l|}{ Original data } \\
\hline Between orchard & 3 & 86.45 & 28.82 & 1.62 & 16.90 & $0.17(0.001)$ \\
\hline Within orchard & 48 & 381.98 & 7.96 & 7.96 & 83.10 & $\ldots$ \\
\hline \multicolumn{7}{|l|}{ Clone-corrected data } \\
\hline Between orchard & 3 & 62.25 & 20.75 & 1.14 & 12.02 & $0.12(0.001)$ \\
\hline Within orchard & 40 & 335.04 & 8.38 & 8.38 & 87.98 & $\ldots$ \\
\hline Total & 43 & 397.29 & 9.24 & 9.52 & 100 & $\ldots$ \\
\hline
\end{tabular}

a AMOVA was performed using poppr (Kamvar et al. 2014). Abbreviations and symbols: $\mathrm{df}=$ degrees of freedom, $\sigma=$ the variance for each hierarchical level, Variation $(\%)=$ the proportion of $\sigma, \phi=$ between-orchard population differentiation, and $P=$ probability of $\phi$ based on a randomization test with 1,000 permutations to determine whether populations were significantly different (i.e., significant population differentiation given that the observed $\phi$ does not fall within the distribution expected from the permutation).
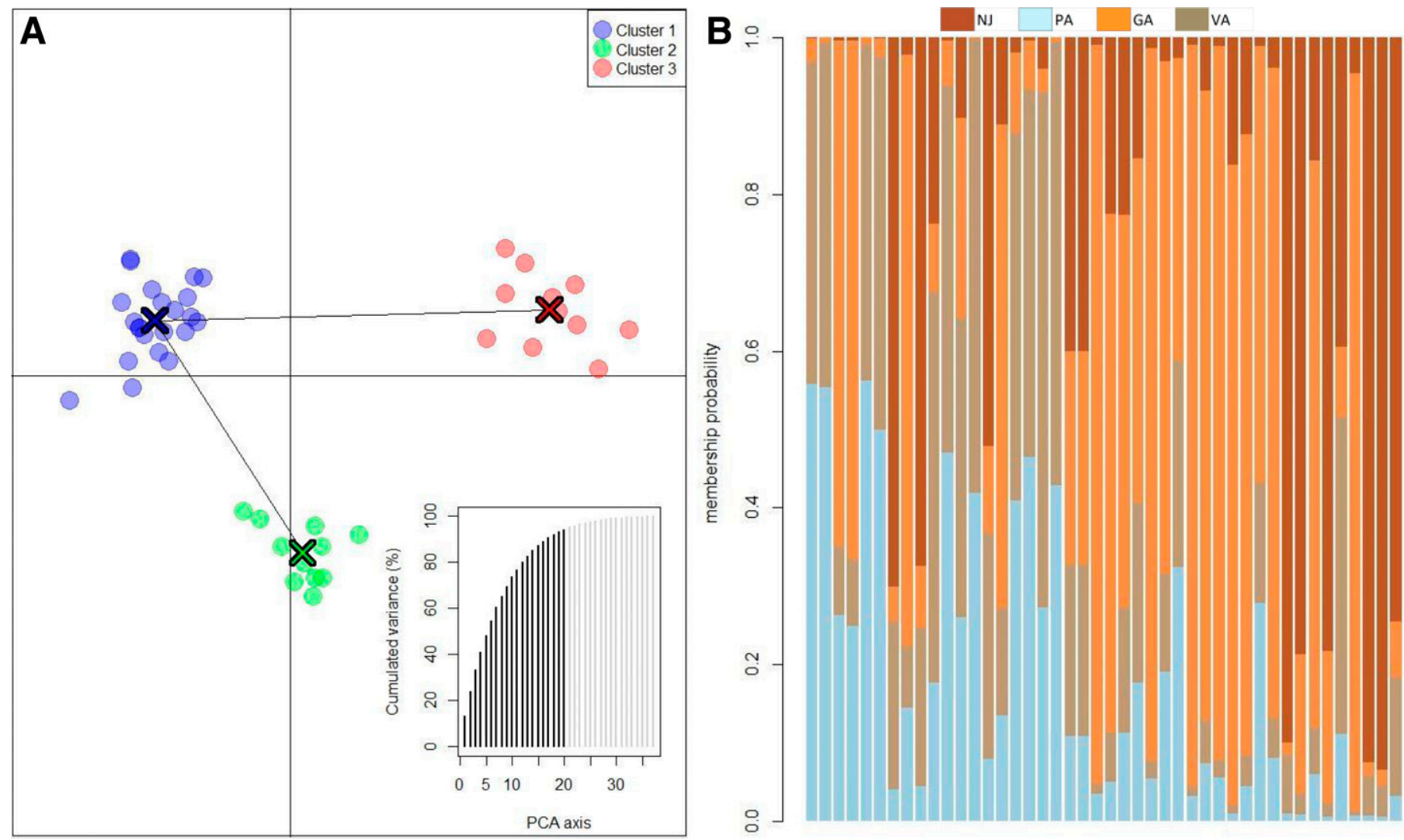

Fig. 5. Results of A, discriminant analysis of principal components based on an analysis of the 43 isolates in the clone-corrected data set characterized by the 16 microsatellite markers from four populations (Berks County and Frederick County, VA; Peach County B, GA; and Cummings County, NJ). A minimum-spanning tree based on the squared distances between the populations is indicated with the center of each group identified by a cross. PCA = principal component analysis. B, Membership probability chart for each of the 43 unique multilocus genotypes from the four populations based on the discriminant analysis of principal components. 
sampled, despite having only five isolates (genotypic and gene diversity data not shown for populations with $<10$ individuals). Each isolate from the nectarine population was a unique MLG.

Private alleles were observed in most populations (not in the Alachua County, FL or Fayette County, KY populations, which had six and one isolates, respectively) (Table 5; Supplementary Fig. S5). The Berks County, PA population had most private alleles (five private alleles in 10 isolates). All other populations had one to two private alleles. The population of $V$. carpophila from nectarine (Oconee County, SC) had a single private allele. All other alleles

\begin{tabular}{|l|l|l|l|}
\hline BER & FRE & PEB & CUM \\
\hline & & & \\
\hline
\end{tabular}

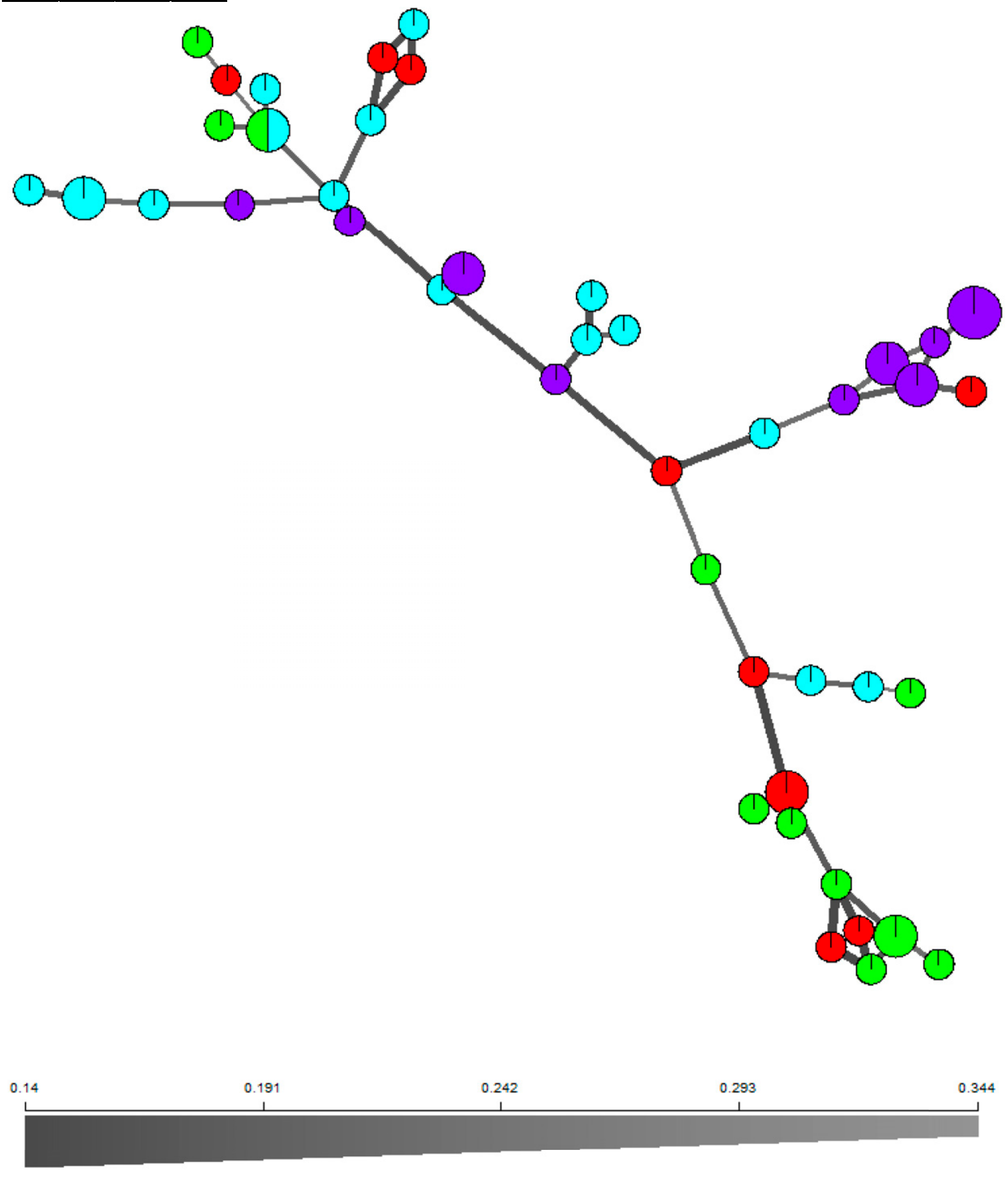

DISTANCE

Fig. 6. Minimum spanning network (MSN) based on the matrix of pairwise Bruvo genetic distances showing the relatedness among multilocus genotypes from populations of Venturia carpophila in four peach orchards in the eastern United States. The MSN was calculated in R using the poppr package (Kamvar et al. 2014). Populations: BER = Berks County, PA; FRE = Frederick County, VA; PEB = Peach County B, GA; and CUM = Cummings County, NJ. Small circles $=$ single isolate, medium circles $=$ two identical isolates (clone), and large circles $=$ three identical isolates (clones). Only two populations shared a clone (FRE and BER). All other clones were restricted to the same population. 
were shared with other populations of $V$. carpophila sampled from peach fruit. Of the total of 73 alleles in all populations, $15(20.5 \%)$ were private alleles. Linkage disequilibrium was observed in both original data and the clone-corrected data using both $I_{A}$ and $\bar{r}_{d}$. With the nonclone-corrected data, seven of the nine populations displayed linkage disequilibrium. With clone correction, five of nine populations showed linkage disequilibrium, demonstrating an effect of clonality. The Oconee, SC population was one of only two populations sampled that showed no linkage disequilibrium based on $I_{A}$ or $\bar{r}_{d}$ (the other was the Peach County A, GA population). Furthermore, for the four populations with most isolates ( $n \geq 10$ isolates: Berks County, PA; Frederick County, VA; Peach County B, GA; and, Cummings County, $\mathrm{NJ})$, linkage disequilibrium $\left(\bar{r}_{d}\right)$ ranged from 0.011 to $0.107(P=0.001$

TABLE 7. Frequencies of mating types (MAT1-1, MAT1-2) of isolates of Venturia carpophila sampled from each of 10 peach orchards in different states and counties in the eastern United States ${ }^{\mathrm{a}}$

\begin{tabular}{lccl}
\hline Analysis, sample & Sample size & MAT1-1: MAT1-2 & $P^{\mathrm{b}}$ \\
\hline Original data & & & \\
Peach County, GA (A) & 4 & $1: 3$ & 0.6 \\
Peach County, GA (B) & 17 & $4: 13$ & $\mathbf{0 . 0 5}$ \\
Decatur County, GA & 5 & $3: 2$ & 1.0 \\
Alachua County, FL & 6 & $4: 2$ & 0.7 \\
Greene County, AL & 8 & $0: 8$ & $\mathbf{0 . 0 0 8}$ \\
Fayette County, KY & 1 & $1: 0$ & NS \\
Berks County, PA & 10 & $7: 3$ & 0.3 \\
Oconee County, SC & 5 & $3: 2$ & 1.0 \\
Cumberland County, NJ & 14 & $12: 2$ & $\mathbf{0 . 0 1}$ \\
Frederick County, VA & 11 & $10: 1$ & $\mathbf{0 . 0 1}$ \\
Total & 81 & $45: 36$ & 0.2 \\
Clone-corrected data & & & \\
Peach County, GA (A) & 4 & $1: 3$ & 0.6 \\
Peach County, GA (B) & 15 & $3: 12$ & $\mathbf{0 . 0 4}$ \\
Decatur County, GA & 4 & $2: 2$ & 1.0 \\
Alachua County, FL & 6 & $4: 2$ & 0.7 \\
Greene County, AL & 7 & $0: 7$ & $\mathbf{0 . 0 2}$ \\
Fayette County, KY & 1 & $1: 0$ & NS \\
Berks County, PA & 9 & $6: 3$ & 0.5 \\
Oconee County, SC & 5 & $3: 2$ & 1.0 \\
Cumberland County, NJ & 9 & $8: 1$ & $\mathbf{0 . 0 4}$ \\
Frederick County, VA & 10 & $9: 1$ & $\mathbf{0 . 0 2}$ \\
Total & 69 & $36: 33$ & 0.8 \\
\hline
\end{tabular}

${ }^{a}$ Original data and clone-corrected data are presented.

b Probability from an exact binomial analysis (two-tailed) to test whether mating-type frequencies deviate significantly from a $1: 1$ ratio. $P$ values in bold indicate populations with loci that deviate significantly from random recombination. to 0.155$)$. Most loci in these populations had no or only moderate evidence of linkage disequilibrium $\left(\bar{r}_{d}>0.25\right)$ (Supplementary Fig. S6).

Based on the four populations with $>10$ isolates, the AMOVA indicated that most variance could be found within orchards for both original $(83.10 \%)$ and clone-corrected $(87.98 \%)$ data sets (Table 6). However, in both cases, population structure could be detected $(\phi P$ $=0.001$ ). Based on the clone-corrected data, the DAPC analysis of the isolates in the four populations indicated that they clustered in three distinct groups (Fig. 5A). Also, estimating cluster number based on the Bayesian information criterion indicated three clusters (Supplementary Fig. S7). The probability of group membership indicated that most isolates had $\geq 20 \%$ probability of membership in two or three of the source populations (Fig. 5B), although a few isolates had almost $100 \%$ membership probability in one population (particularly some isolates from the Berks County, NJ and Peach County B, GA populations). The MSN based on Bruvo's distance indicated that, although there was a slight tendency for individuals from the same population to group (Fig. 6), there were individuals in all populations that had closely related MLGs from the other three populations. Isolate numbers in these four populations were still limited; therefore, the results are considered only suggestive of some possible underlying population structure.

Mating-type frequency and genetic structure. The frequency of MAT1-1 and MAT1-2 mating types varied among orchards but sample sizes in all cases were small $(n \leq 14)$ (Table 7). Clonality existed in six of the orchard samples (Peach County B, GA; Green County, AL; Cumberland County, NJ; and Frederick County, VA) but in no case did clone correction change the outcome of the exact binomial test. In all orchards with at least two isolates, both mating types were identified, except the one in Greene County, AL. In Greene County all eight isolates were MAT1-2. In all orchards, except those in Peach County, the number of MAT1-1 isolates was greater than MAT1-2 isolates. The frequency of mating types of isolates of $V$. carpophila from nectarine (Oconee County, SC) were in equilibrium when analyzed based on original data or the clone-corrected data. Overall, there was no evidence that the mating types were not in equilibrium for either all original location data combined (MAT1-1/MAT1-2, 45:36), or the clone-corrected data (MAT1-1/MAT1-2, 36:33). For the clone-corrected data, the exact binomial test $(P=0.8)$ of mating-type frequencies in this widely sourced selection of isolates from the eastern United States demonstrated mating types to be in equilibrium at the regional scale.

The two mating-type populations were genetically diverse groups, with very similar measures for both genotypic and gene

TABLE 8. Statistics summarizing the genetic variation (genotypic and genic) within the two mating type populations of Venturia carpophila

\begin{tabular}{|c|c|c|c|c|c|c|c|c|}
\hline Analysis, mating type & $N^{\mathrm{b}}$ & $\mathrm{MLG}^{\mathrm{c}}$ & eMLG $(\mathrm{SE})^{\mathrm{d}}$ & $\mathrm{H}^{\mathrm{e}}$ & $\mathrm{G}^{\mathrm{f}}$ & $\lambda g$ & $E .5^{\text {h }}$ & $\mathrm{H}_{\exp }{ }^{i}$ \\
\hline \multicolumn{9}{|l|}{ Original data } \\
\hline MAT1-1 & 45 & 36 & $30.0(1.20)$ & 3.51 & 30.2 & 0.967 & 0.904 & 0.592 \\
\hline MAT1-2 & 36 & 33 & $33.0(0.00)$ & 3.47 & 30.9 & 0.968 & 0.961 & 0.581 \\
\hline \multicolumn{9}{|l|}{ Clone-corrected data } \\
\hline MAT1-1 & 36 & 36 & - & 3.58 & 36 & 0.972 & - & 0.600 \\
\hline$M A T 1-2$ & 33 & 33 & - & 3.50 & 33 & 0.970 & - & 0.580 \\
\hline
\end{tabular}

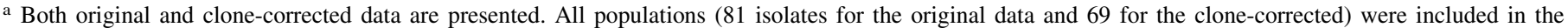
analysis. Analyses were performed using poppr (Kamvar et al. 2014); - indicates that result was meaningless for clone-corrected data.

b Number of individuals in the population.

c Number of multilocus genotypes (MLGs) in that population.

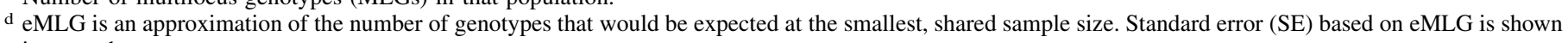
in parentheses.

e Shannon-Wiener Index of MLG diversity (Shannon 2001).

f Stoddart and Taylor's measure of genotypic diversity (Stoddart and Taylor 1988).

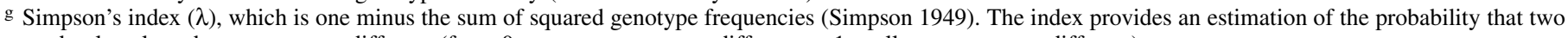
randomly selected genotypes are different (from $0=$ no genotypes are different to $1=$ all genotypes are different).

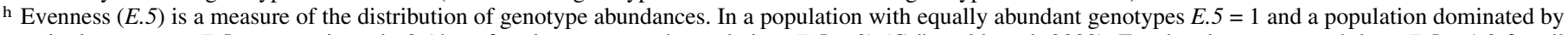
a single genotype $E .5=$ approximately 0 (thus, for clone-corrected population, $E .5=0$ ) (Grünwald et al. 2003 ). For the clone-corrected data, $E .5=1.0$ for all populations.

i Nei's unbiased estimate of average heterozygosity (or gene diversity) (Nei 1978). 
diversity whether the data were original or clone corrected (Table 8). The Shannon-Wiener index of MLG diversity was 3.51 and 3.47 for MAT1-1 and MAT1-2 for the original data and 3.58 and 3.50 for the clone-corrected data, respectively. Other measures of genotypic diversity $(\mathrm{G}$ or $\lambda)$ were similar. Gene diversity was 0.592 and 0.581 for MAT1-1 and MAT1-2 for the original data and 0.600 and 0.580 for the clone-corrected data, respectively. MAT1-2 had slightly more equally abundant genotypes (0.961) compared with MAT1-1 (0.904), due to the greater number of clones in MAT1-1 (10).

There were private alleles within both mating-type groups (Table 9; Supplementary Fig. S8). MAT1-1 had 11 private alleles, while MAT1-2 had 9 private alleles. Sample sizes were limited, which could explain the presence of private alleles within the sampled populations. Linkage disequilibrium measured as $I_{A}$ and $\bar{r}_{d}$ was prevalent in both mating types in both the original and clonecorrected data sets. As with the population-level data, only a few pairwise comparisons of loci had low to moderate linkage disequilibrium $\left(\bar{r}_{d}>0.1\right)$ (Supplementary Fig. S9).

Based on the two mating types, the AMOVA indicated that almost all variance could be accounted for within the mating types for both original (98.56\%) and clone-corrected (99.69\%) data sets (Table 10). In the case of the original data, population structure between mating types could be detected $(\phi P=0.04)$. However, when clone corrected, there was no evidence of any population structure between mating types $(\phi P=0.3)$. Based on the clonecorrected data, and as for the population level results, the DAPC analysis indicated that they clustered in three distinct groups (Fig. 7A). The probability of group membership indicated that most isolates had an approximately $50 \%$ probability of membership to either mating type, although slightly more isolates tended to show greater membership to MAT1-2 (Fig. 7B). The MSN based on Bruvo's distance indicated little tendency for individuals from either mating type to group (Fig. 8), and there were individuals from both mating types distributed throughout the network. Although the sample size and sampling structure did not allow for analyzing genetic characteristics at the suborchard level, the data do confirm that different mating types exist within the same peach tree canopy (Supplementary Table S4).

\section{DISCUSSION}

This study is the first to define and characterize the mating types of $V$. carpophila and the genetic diversity within the species based on previously developed microsatellites (Chen et al. 2018). $V$. carpophila was identified as a heterothallic species, a mode of sexual reproduction that it shares with several other Venturia spp. (Keitt and Palmitter 1937; Langford and Keitt 1942; Young et al. 2018). The structure of the mating-type loci in V. carpophila is conserved with that of other Venturia spp. ( $V$. effusa and $V$. inaequalis). The structure of the two mating-type idiomorphs confirmed the presence of the $\alpha$-box and the HMG-box, described for several other closely related ascomycetes. Interestingly, although the MAT1-1-1 gene contained an intron, it was not associated with the $\alpha$-box as has been found with other fungal species. The sequence alignments of the mating-type genes showed greatest identity to $V$. effusa, followed by $V$. inaequalis. This was consistent with the phylogenetic analysis of TUB2, which indicated that $V$. carpophila was most closely related to $V$. effusa. This result lends weight to the phylogeny described from earlier observations by Schnabel et al. (1999), who used sequence from the ITS1-5.8SITS2 region of Venturia and Cladosporium spp. These results also support the taxonomic positions as defined by Schubert et al. (2003) for Fusicladium carpophilum (syn. V. carpophila).

A sexual stage has been described for V. carpophila (Fisher 1961). However, this was described from apricot freckle fungus in Victoria, Australia. The pathogen is also reported to infect almond (Teviotdale et al. 2002). Based on the TUB2 phylogenetic analysis, an isolate from almond (MN548431) grouped with the isolates of $V$. carpophila from peach and nectarine. We found no evidence that

TABLE 9. Measures of random mating between the two mating types (MAT1-1 and MAT1-2) of Venturia carpophila from 10 peach orchards in the eastern United States

\begin{tabular}{|c|c|c|c|c|c|c|c|}
\hline \multirow[b]{2}{*}{ Type $^{c}$} & \multicolumn{2}{|c|}{$\begin{array}{l}\text { Number of } \\
\text { individuals }^{\mathrm{a}}\end{array}$} & \multirow[b]{2}{*}{ Alleles $^{\mathrm{d}}$} & \multicolumn{2}{|c|}{ Original datab } & \multicolumn{2}{|c|}{ Clone-corrected data ${ }^{\mathrm{b}}$} \\
\hline & Orig & Clone & & $I_{A}(P$ value $)$ & $\bar{r}_{d}(P$ value $)$ & $I_{A}(P$ value $)$ & $\bar{r}_{d}(P$ value $)$ \\
\hline MAT1-1 & 45 & 36 & 11 & $0.842(0.001)$ & $0.056(0.001)$ & $0.460(0.001)$ & $0.031(0.001)$ \\
\hline
\end{tabular}

a Mean number of alleles. Orig = original data and Clone $=$ clone-corrected data.

b Gametic disequilibrium measured using the index of association $\left(I_{A}\right)$ and the standardized index of association $\left(\bar{r}_{d}\right)$, for both the original data and the clonecorrected data. $I_{A}$ is a measure of linkage disequilibrium. The $\bar{r}_{d}$ is a more robust measure, less sensitive to the number of loci (Agapow and Burt 2001; Brown et al. 1980; Smith et al. 1993). Statistics were calculated based on 1,000 randomizations. Analyses were performed using poppr (Kamvar et al. 2014). Data in bold indicate populations with loci that deviate significantly from random recombination.

c Mating type. All populations (81 isolates for the original data and 69 for the clone-corrected) were included in the analysis.

d Number of private alleles. A private allele is one unique to that population. There were 73 alleles among the 16 loci over all 81 isolates sampled.

TABLE 10. Analysis of molecular variance (AMOVA) of the population structure by mating type of Venturia carpophila collected from peach fruit in 10 different orchards in the eastern United States based on both original and clone-corrected data ${ }^{\mathrm{a}}$

\begin{tabular}{|c|c|c|c|c|c|c|}
\hline Analysis, source & df & Sum of squares & Mean squares & $\sigma$ & Variation $(\%)$ & $\phi(P$ value $)$ \\
\hline \multicolumn{7}{|l|}{ Original data } \\
\hline Between mating types & 1 & 14.94 & 14.94 & 0.14 & 1.44 & $0.01(0.04)$ \\
\hline Within mating types & 79 & 744.31 & 9.42 & 9.42 & 98.56 & $\ldots$ \\
\hline \multicolumn{7}{|l|}{ Clone-corrected data } \\
\hline Between mating types & 1 & 10.50 & 10.50 & 0.03 & 0.31 & $0.003(0.3)$ \\
\hline Within mating types & 67 & 635.41 & 9.48 & 9.48 & 99.69 & $\ldots$ \\
\hline Total & 68 & 645.91 & 9.50 & 9.51 & 100.0 & $\ldots$ \\
\hline
\end{tabular}

a AMOVA was performed using poppr (Kamvar et al. 2014). Abbreviations and symbols: $\mathrm{df}=$ degrees of freedom, $\sigma=$ the variance for each hierarchical level, Variation $(\%)=$ the proportion of $\sigma, \phi=$ between-mating-type population differentiation, and $P=$ probability of $\phi$ based on a randomization test with 1,000 permutations to determine whether mating-type populations were significantly different (i.e., with the clone-corrected data, no significant population differentiation given that the observed $\phi$ does not fall within the distribution expected from the permutation). 
the isolates sampled from nectarine (Oconee County, SC) were genetically different from those sampled from peach elsewhere. Measures of genotypic and gene diversity, and the observation that all but one allele was shared with other peach populations at comparable frequencies, is indicative that there is transfer of genetic material among the populations infecting peach and nectarine. This may not be surprising because nectarine is considered a smoothskinned peach (P. persica). To the best of our knowledge, host range studies have not been performed with isolates collected from the three hosts peach, apricot, and almond; population genetic studies need to be performed to ascertain whether the populations from the hosts are freely recombining. There may be areas of the world where the populations of $V$. carpophila on these three hosts coexist sympatrically. However, in many areas (such as Peach County, GA in the southeastern United States), only one host species is cultivated. In California, peach and almond are both cultivated but it is not known whether the pathogen populations on these crops are freely mixing.

The results of this study demonstrate that both mating types can coexist in the same orchards and the same tree in the southeastern United States and, thus, the potential for sexual recombination is available. Insufficient samples were taken from individual fruit to ascertain whether both coexisted on a single fruit (only one fruit was sampled for multiple isolates). This has ramifications for the epidemiology of the disease, because more than one spore type may play a role in the disease cycle. Currently, the epidemiology of peach scab in the eastern United States is based on a model defining the importance of the splash-dispersed asexually produced conidia (Keitt 1917; Lan and Scherm 2003; Scherm et al. 2008), yet a sexually produced ascospore could play a significant role in disease spread. With the apple scab pathogen, although ascospores are known to be a major inoculum source (MacHardy 1996), locally asexually produced and locally dispersed conidia may also be important in the epidemic at small spatial scales (Xu et al. 2013).

Primers to MAT1-1-1 and MAT1-2-1 genes were developed that effectively amplified parts of the gene in the presence of a primer for a housekeeping gene (TUB2), with the reaction being multiplexed to facilitate efficiency and economy of identification in large numbers of isolates. Although preliminary, due to sample sizes, both nonclone-corrected and clone-corrected data show that the two mating types of $V$. carpophila exist in equilibrium in over half the populations and overall. In several cases, both mating types were observed in the same tree canopy. However, in individual orchards, the numbers were small, as has been the case in some other studies such as with Rhynchosporium secalis (Linde et al. 2003) and D. septosporum (Dale et al. 2011). The suggestion of mating-type equilibrium we observed in some populations indicates that the fungus is undergoing sexual reproduction at sufficient frequency to ensure equivalent frequency of mating types. Mating-type frequencies of many other sexually reproducing filamentous ascomycetes are in equilibrium in most populations, especially when sample size is sufficient (Gout et al. 2006; Sommerhalder et al. 2006). Mating types have also been found in equilibrium in some species of filamentous ascomycetes for which a sexual stage has not yet been identified (Linde et al. 2003). As noted, both mating types were found in the same peach tree canopies, indicating that they may be spatially close. Sampling at a small spatial scale will reveal whether the two mating types are found on the same fruit.

Although structural organization of the two mating-type loci and regions of the $\alpha$ - and HMG-box sequences may have similarity, they are characteristic for individual species (Turgeon 1998). It is important to identify and characterize the mating-type genes
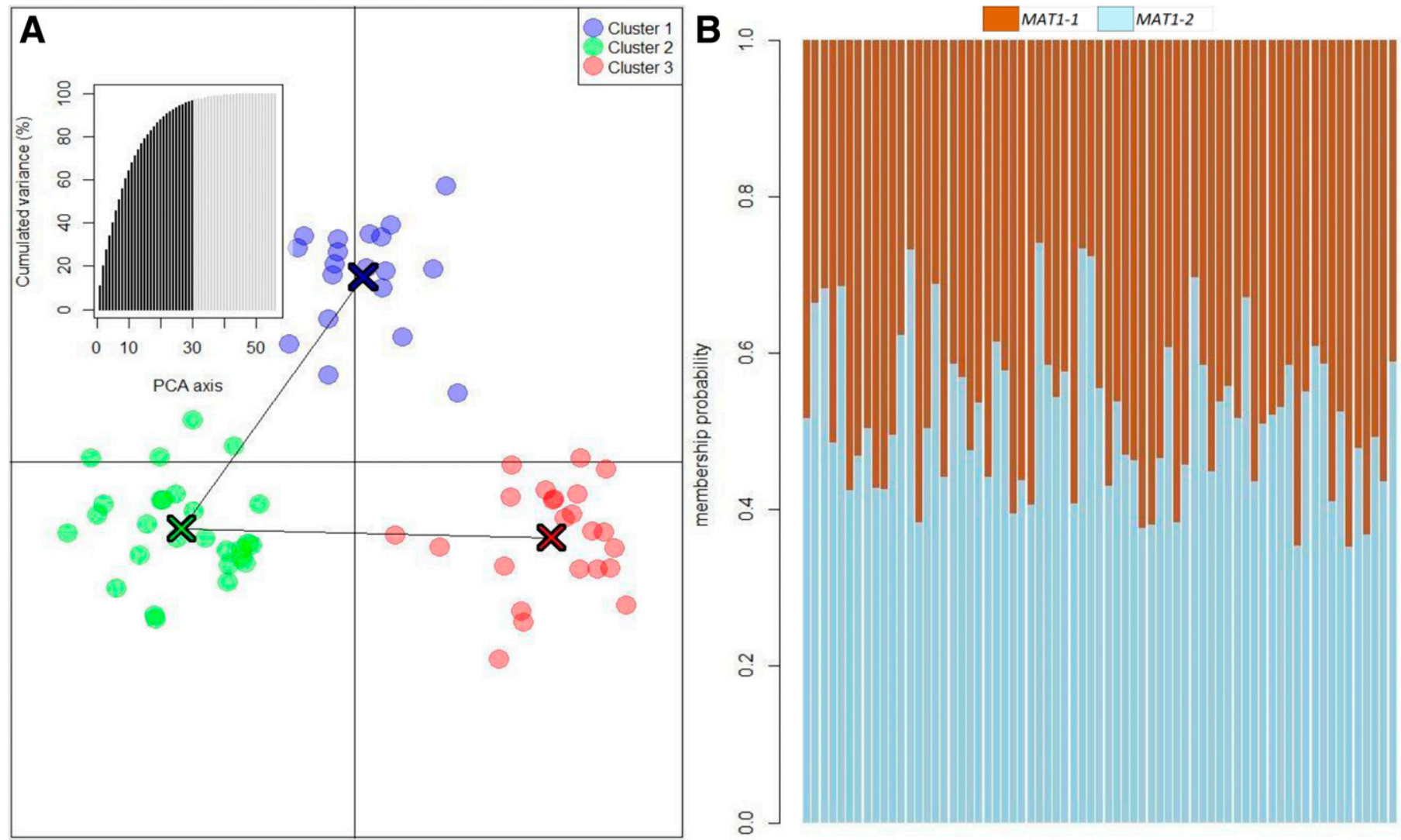

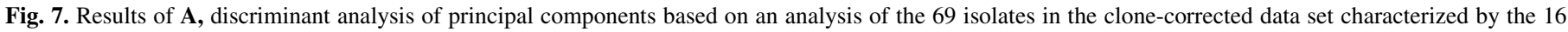

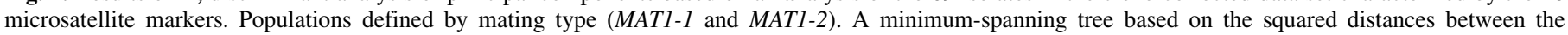

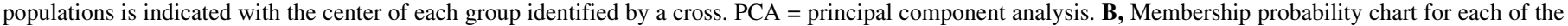
69 unique multilocus genotypes from the two mating types based on the discriminant analysis of principal components. 
because they can be indicators of the reproductive strategy, which can directly affect diversity. These results indicate that sexual reproduction is likely a component of the lifecycle of $V$. carpophila in the eastern United States. Indeed, the population genetic characteristics and balance of mating types of the closely related V. effusa were initially indicative of a sexual stage (Bock et al. 2017; Young et al. 2018), which was only very recently characterized for that species (Charlton et al. 2020). The sexual stage of $V$. carpophila has been described in Australia (Fisher 1961) but its likely presence and possible role in the United States has remained uncharacterized prior to this study.

The populations were genetically diverse (both genotypic and gene diversity). Most isolates of $V$. carpophila were unique MLGs and, although some clones (12 isolates overall) were found, this

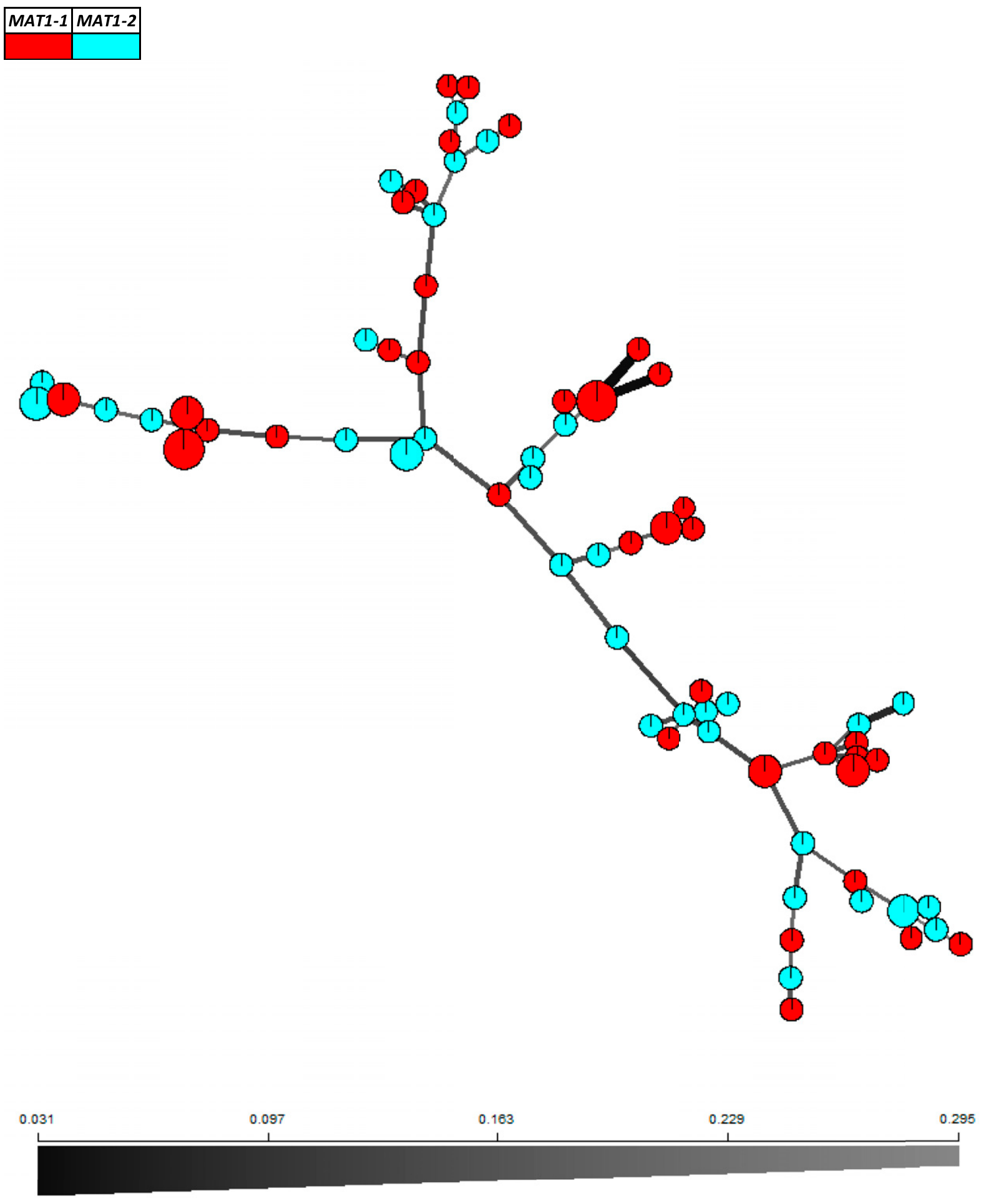

\section{DISTANCE}

Fig. 8. Minimum spanning network (MSN) based on the matrix of pairwise Bruvo genetic distances showing the relatedness among multilocus genotypes from populations of Venturia carpophila from the two mating types (MAT1-1 and MAT1-2) from 10 peach orchards in the eastern United States. The MSN was calculated in $\mathrm{R}$ using the poppr package (Kamvar et al. 2014). Small circles $=$ single isolate, medium circles $=$ two identical isolates $($ clone $)$, and large circles $=$ three identical isolates (clones). 
might be expected when considering that a small-scale, splashdispersed component is described for V. carpophila (Keitt 1917; Lan and Scherm 2003; Scherm et al. 2008), especially because all but one of the clones were from trees in the same orchard (that might have been adjacent) or from fruit in the same canopy (and those fruit might have been adjacent). Such proximity would increase the chance of the clones being from the same inoculum source. The genotypic and genetic diversity observed among these 81 isolates of $V$. carpophila is suggestive of a sexually reproducing pathogen; however, there was evidence of linkage disequilibrium in most populations. Linkage disequilibrium might be due to spatially restricted epidemics, close physical association among loci, selection processes, gene flow and drift (Milgroom 1996), or a clonal component due to the reproduction of the pathogen (McDonald 2004) or, possibly, the sampling. In most cases, only some of the pairwise loci comparisons demonstrated severe disequilibrium; thus, it was likely biased by these pairs. However, the loci were carefully selected based on even coverage of the entire genome, thus avoiding risk of linkage caused by physical proximity (Chen et al. 2018). In other studies, linkage disequilibrium was observed in populations of both the closely related $V$. effusa on pecan (Bock et al. 2017) and V. inaequalis on apple (Xu et al. 2013), both of which have a sexual stage. Private alleles were observed both within individual populations and between mating types but did not appear to be associated with the size of the population. Nonetheless, private alleles may indicate some degree of population differentiation. Sampling using hierarchical approaches and larger sample sizes will provide more definitive results on these aspects of populations of $V$. carpophila.

For the four population with sufficient numbers of isolates $(\geq 10$ isolates), there was evidence of population structure. The AMOVA indicated that, although most variance was explicable at the level of the population, a smaller proportion $(12.02 \%$ for the clonecorrected data) was accountable between orchards. The DAPC and MSN both provided additional evidence of genetic clustering, although all analyses indicated considerable admixture and relatedness among many individual isolates from most populations as well. The AMOVA based on mating type using clone-corrected data showed no evidence of population structure $(99.69 \%$ of the variance was explicable within the mating-type populations) but the DAPC of these isolates did identify three distinct genetic clusters, confirming the result from the population-level DAPC. The membership probabilities based on mating type tended to show a reasonably even admixture for most isolates. The MSN of these data bore out this result. Isolates from the two mating types did not show any marked evidence of clustering associated with mating type. These data are also indicative that sexual reproduction is likely occurring among populations of V. carpophila in the eastern United States. However, as noted above, larger samples of isolates from several trees in several orchards are needed to confirm what these data indicate and define more clearly the genetic diversity, reproduction, and population structure.

Phytosanitary regulation may be affected by the existence of single mating types of a fungus in some areas; for example, black spot of citrus (Wang et al. 2016) and Dothistroma needle blight of pine (Groenewald et al. 2006). It is not known whether both mating types of $V$. carpophila exist in all other peach-, apricot-, and almond-producing areas but, clearly, this should be ascertained because these stone fruit are introduced crops in most areas where they are cultivated. Cooccurrence of both mating types provides the opportunity for sexual reproduction, which is the vehicle for recombination and reassortment of existing and novel genetic variability. Such variability is an important basis for adaptability, and this can affect any endeavors to manage the disease through resistance breeding, as well as affect development and propagation of fungicide resistance (McDonald 2015; McDonald and Linde 2002; McDonald and Mundt 2016). Both mating types of V. carpophila exist in the eastern United States and were demonstrated to exist in the southeast of Australia because the sexual cycle was observed (Fisher 1961) but their existence is uncharted in the western United States, South America, parts of Africa, and other locations where these stone fruit are produced and peach scab occurs (Keitt 1917). Knowledge of the occurrence of mating types on stone fruit in other areas would be useful.

The ability to identify mating types of $V$. carpophila provides a basis for characterizing populations in different stone fruit production areas where scab is an issue, which can provide insights into reproductive methods and is a basis for studying the genetics of the fungus through in vitro crosses of opposite mating types. It may also provide a basis for an improved understanding of the epidemiology of the disease, and possible management opportunities to achieve better scab control.

\section{ACKNOWLEDGMENTS}

We thank W. Evans, K. Carson, S. Burrell, and J. Shipp for their technical help; K. Yoder (Virginia Tech Agricultural Research and Extension Center), G. Schnabel and K. Bryson (Clemson University), K. Peter (Penn State Fruit Research and Extension Center), N. Gauttier (University of Kentucky), N. Lalancette (Rutgers), M. Olmstead (University of Florida), D. Ritchie (North Carolina State University), and T. Beckman (United States Department of Agriculture-Agricultural Research Service-Southeastern Fruit and Tree Nut Research Laboratory) for collecting diseased samples of peach from which the isolates were obtained; and N. Krom (Noble Research Institute) for assembly of the PS1-1 genome. This article reports the results of research only. Mention of a trademark or proprietary product is solely for the purpose of providing specific information and does not constitute a guarantee or warranty of the product by the U.S. Department of Agriculture and does not imply its approval to the exclusion of other products that may also be suitable.

\section{LITERATURE CITED}

Agapow, P. M., and Burt, A. 2001. Indices of multilocus linkage disequilibrium. Mol. Ecol. Notes 1:101-102.

Anonymous. 2004. United States Standards for grades of peaches. U.S. Department of Agriculture, Agricultural Marketing Service, Fruit and Vegetable Division, Fresh Products Branch, Washington, DC. https://www.ams.usda. gov/sites/default/files/media/Peach_Standard\%5B1\%5D.pdf

Arie, T., Christiansen, S., Yoder, O., and Turgeon, B. 1997. Efficient cloning of ascomycete mating type genes by PCR amplification of the conserved MAT HMG Box. Fungal Genet. Biol. 21:118-130.

Bankevich, A., Nurk, S., Antipov, D., Gurevich, A. A., Dvorkin, M., Kulikov, A. S., Lesin, V. M., Nikolenko, S. I., Pham, S., Prjibelski, A. D., Pyshkin, A. V., Sirotkin, A. V., Vyahhi, N., Tesler, G., Alekseyev, M. A., and Pevzner, P. A. 2012. SPAdes: A new genome assembly algorithm and its applications to single-cell sequencing. J. Comput. Biol. 19:455-477.

Bock, C. H., Hotchkiss, M. W., Okie, W. R., and Wood, B. W. 2011. The distribution of peach scab lesions on the surface of diseased peaches. Eur. J. Plant Pathol. 130:393-402.

Bock, C. H., Hotchkiss, M. W., Young, C. A., Charlton, N. D., Mattupalli, C., Stevenson, K. L., and Wood, B. W. 2017. Population genetic structure of Venturia effusa, cause of pecan scab, in the southeastern United States. Phytopathology 107:607-619.

Bock, C. H., Young, C. A., Stevenson, K. L., and Charlton, N. D. 2018. Finescale population genetic structure and within-tree distribution of mating types of Venturia effusa, cause of pecan scab in the United States. Phytopathology 108:1326-1336.

Botstein, D., White, R. L., Skolnick, M., and Davis, R. W. 1980. Construction of a genetic linkage map in man using restriction fragment length polymorphisms. Am. J. Hum. Genet. 32:314-331.

Brown, A. H. D., Feldman, M. W., and Nevo, E. 1980. Multilocus structure of natural populations of Hordeum spontaneum. Genetics 96:523-536.

Charlton, N. D., Yi, M., Bock, C. H., Zhang, M., and Young, C. A. 2020. First description of the sexual stage of Venturia effusa, causal agent of pecan scab. Mycologia 112:711-721.

Chen, C., Bock, C. H., Brannen, P. M., and Adaskaveg, J. E. 2018. Mining and characterization of microsatellites from a genome of Venturia carpophila. Mycol. Prog. 17:885-895.

Chen, C., Bock, C. H., Brannen, P. M., Adaskaveg, J. E., Hotchkiss, M. W., Brewer, M. T., and Wood, B. W. 2014. Genetic variability among populations of Fusicladium species from different host trees and geographic locations in the USA. Mycol. Prog. 13:1006. 
Chen, C., Bock, C. H., and Wood, B. W. 2017. Draft genome sequence of Venturia carpophila, the causal agent of peach scab. Stand. Genomic Sci. 12:68.

Chilvers, M. I., Jones, S., Meleca, J., Peever, T. L., Pethybridge, S. J., and Hay, F. S. 2014. Characterization of mating type genes supports the hypothesis that Stagonosporopsis chrysanthemi is homothallic and provides evidence that Stagonosporopsis tanaceti is heterothallic. Curr. Genet. 60:295-302.

Dale, A., Lewis, K., and Murray, B. 2011. Sexual reproduction and gene flow in the pine pathogen Dothistroma septosporum in British Columbia. Phytopathology 101:68-76.

Dereeper, A., Audic, S., Claverie, J.-M., and Blanc, G. 2010. BLAST-EXPLORER helps you building datasets for phylogenetic analysis. BMC Evol. Biol. 10:8.

Dereeper, A., Guignon, V., Blanc, G., Audic, S., Buffet, S., Chevenet, F., Dufayard, J.-F., Guindon, S., Lefort, V., and Lescot, M. 2008. Phylogeny.fr: Robust phylogenetic analysis for the non-specialist. Nucleic Acids Res. 36: W465-W469.

Edgar, R. C. 2004. MUSCLE: Multiple sequence alignment with high accuracy and high throughput. Nucleic Acids Res. 32:1792-1797.

Fisher, E. E. 1961. Venturia carpophila sp. nov., the ascigerous state of the apricot freckle fungus. Trans. Br. Mycol. Soc. 44:337-342, IN3-IN4.

Gladieux, P., Zhang, X. G., Afoufa-Bastien, D., Valdebenito Sanhueza, R. M., Sbaghi, M., and Le Cam, B. 2008. On the origin and spread of the scab disease of apple: Out of central Asia. PLoS One 3:e1455.

Gout, L., Eckert, M., and Rouxel, T. 2006. Genetic variability and distribution of mating type alleles in field populations of Leptosphaeria maculans from France. Appl. Environ. Microbiol. 72:185-191.

Groenewald, M., Groenewald, J. Z., Harrington, T. C., Abeln, E. C., and Crous, P. W. 2006. Mating type gene analysis in apparently asexual Cercospora species is suggestive of cryptic sex. Fungal Genet. Biol. 43: 813-825.

Grünwald, N. J., Everhart, S. E., Knaus, B. J., and Kamvar, Z. N. 2017. Best practices for population genetic analyses. Phytopathology 107:1000-1010.

Grünwald, N. J., Goodwin, S. B., Milgroom, M. G., and Fry, W. E. 2003. Analysis of genotypic diversity data for populations of microorganisms. Phytopathology 93:738-746.

Guindon, S., Dufayard, J.-F., Lefort, V., Anisimova, M., Hordijk, W., and Gascuel, O. 2010. New algorithms and methods to estimate maximumlikelihood phylogenies: Assessing the performance of PhyML 3.0. Syst. Biol. 59:307-321.

Henk, D. A., Shahar-Golan, R., Devi, K. R., Boyce, K. J., Zhan, N., Fedorova, N. D., Nierman, W. C., Hsueh, P.-R., Yuen, K.-Y., Sieu, T. P. M., Kinh, N. V., Wertheim, H., Baker, S. G., Day, J. N., Vanittanakom, N., Bignell, E. M., Andrianopoulos, A., and Fisher, M. C. 2012. Clonality despite sex: The evolution of host-associated sexual neighborhoods in the pathogenic fungus Penicillium marneffei. PLoS Pathog. 8:e1002851.

Jombert, T., Kamvar, Z. N., Collins, C., Lustrik, R., Beugin, M.-P., Knaus, P. J., Solymos, P., Mikryukov, V., Schliep, K., Maie, T., Morkovsky, L., Ahmed, I., Cori, A., Calboli, F., and Ewing, R. J. 2018. Package 'adegenet': Exploratory Analysis of Genetic and Genomic Data v 2.1.1. https://cran.rproject.org/web/packages/adegenet/adegenet.pdf

Kamvar, Z. N., Tabima, J. F., and Grünwald, N. J. 2014. Poppr: An R package for genetic analysis of populations with clonal, partially clonal, and/or sexual reproduction. PeerJ 2:e281.

Keitt, G. W. 1917. Peach scab and its control. U. S. Dep. Agric. Bull. 395.

Keitt, G. W., and Palmitter, G. H. 1937. Heterothallism in Venturia inaequalis. Science 85:798.

Lan, Z., and Scherm, H. 2003. Moisture sources in relation to conidial dissemination and infection by Cladosporium carpophilum within peach canopies. Phytopathology 93:1581-1586.

Langford, M. H., and Keitt, E. N. 1942. Heterothallism and variability in Venturia pirina. Phytopathology 32:357-369.

Lawrence, E. G., Jr., and Zehr, E. I. 1982. Environmental effects on the development and dissemination of Cladosporium carpophilum on peach. Phytopathology 72:773-776.

Linde, C. C., Zala, M., Ceccarelli, S., and McDonald, B. A. 2003. Further evidence for sexual reproduction in Rhynchosporium secalis based on distribution and frequency of mating-type alleles. Fungal Genet. Biol. 40: 115-125.

Linde, C. C., Zala, M., and McDonald, B. A. 2009. Molecular evidence for recent founder populations and human-mediated migration in the barley scald pathogen Rhynchosporium secalis. Mol. Phylogenet. Evol. 51:454-464.

Linde, C. C., Zhan, J., and McDonald, B. A. 2002. Population structure of Mycosphaerella graminicola: From lesions to continents. Phytopathology 92:946-955

Ludwig, J. A., and Reynolds, J. F. 1988. Statistical Ecology: A Primer in Methods and Computing. Wiley-Interscience, Hoboken, NJ, U.S.A.

MacHardy, W. E. 1996. Apple Scab: Biology, Epidemiology, and Management. American Phytopathological Society, St. Paul, MN, U.S.A.
McDonald, B. A. 2004. Population genetics of plant pathogens. Plant Health Instruct. https://www.apsnet.org/edcenter/disimpactmngmnt/topc/PopGenetics/Pages/default.aspx

McDonald, B. A. 2015. How can research on pathogen population biology suggest disease management strategies? The example of barley scald (Rhynchosporium commune). Plant Pathol. 64:1005-1013.

McDonald, B. A., and Linde, C. 2002. Pathogen population genetics, evolutionary potential, and durable resistance. Annu. Rev. Phytopathol. 40:349-379.

McDonald, B. A., and Mundt, C. C. 2016. How knowledge of pathogen population biology informs management of Septoria tritici blotch. Phytopathology 106:948-955.

Milgroom, M. G. 1996. Recombination and the multilocus structure of fungal populations. Annu. Rev. Phytopathol. 34:457-477.

Nei, M. 1978. Estimation of average heterozygosity and genetic distance from a small number of individuals. Genetics 89:583-590.

Ogawa, J. M., Zehr, E. I., Bird, G. W., Ritchie, D. F., Uriu, K., and Uyemoto, J. K., eds. 1995. Compendium of Stone Fruit Diseases. American Phytopathology Society, St. Paul., MN, U.S.A.

Pearce, T. L., Scott, J. B., Hay, F. S., and Pethybridge, S. J. 2016. Mating-type gene structure and spatial distribution of Didymella tanaceti in pyrethrum fields. Phytopathology 106:1521-1529.

Pielou, E. C. 1975. Ecological Diversity. John Wiley \& Sons, New York, NY, U.S.A.

Pöggeler, S. 2001. Mating-type genes for classical strain improvement of ascomycetes. Appl. Microbiol. Biotechnol. 56:589-601.

Priyam, A., Woodcroft, B. J., Rai, V., Moghul, I., Munagala, A., Ter, F., Chowdhary, H., Pieniak, I., Maynard, L. J., Gibbins, M. A., and Moon, H. 2019. Sequenceserver: A modern graphical user interface for custom BLAST databases. Mol. Biol. Evol. 36:2922-2924.

Ramirez-Prado, J. H., Moore, G. G., Horn, B. W., and Carbone, I. 2008. Characterization and population analysis of the mating-type genes in Aspergillus flavus and Aspergillus parasiticus. Fungal Genet. Biol. 45: 1292-1299.

Rau, D., Maier, F. J., Papa, R., Brown, A. H., Balmas, V., Saba, E., Schaefer, W., and Attene, G. 2005. Isolation and characterization of the mating-type locus of the barley pathogen Pyrenophora teres and frequencies of matingtype idiomorphs within and among fungal populations collected from barley landraces. Genome 48:855-869.

R Core Team. 2018. R: A Language and Environment for Statistical Computing. R Foundation for Statistical Computing, Vienna, Austria. https:// www.R-project.org/

Scherm, H., and Brannen, P. M. 2005. Peach scab. Pages 134-136 in: Southeastern Peach Growers' Handbook. D. Horton and D. Johnson, eds. University of Georgia, Cooperative Extension, G.E.S. Handbook No. 1. College of Agricultural and Environmental Sciences, Athens, GA, U.S.A.

Scherm, H., Savelle, A. T., Boozer, R. T., and Foshee, W. G. 2008. Seasonal dynamics of conidial production potential of Fusicladium carpophilum in southeastern peach orchards. Plant Dis. 92:47-50.

Schnabel, G., Schnabel, E. L., and Jones, A. L. 1999. Characterization of ribosomal DNA from Venturia inaequalis and its phylogenetic relationship to rDNA from other tree-fruit Venturia species. Phytopathology 89:100-108.

Schubert, K., Ritschel, A., and Braun, U. 2003. A monograph of Fusicladium s.lat. (Hyphomycetes). Schlechtendalia 9:1-132.

Shannon, C. E. 2001. A mathematical theory of communication. ACM SIGMOBILE Mob. Comput. Commun. Rev. 5:3-55.

Shannon, C. E., and Weaver, W. 1949. The mathematical theory of communication. University of Illinois Press.

Simpson, E. 1949. Measurement of diversity. Nature 163:688.

Smith, J. M., Smith, N. H., O’Rourke, M., and Spratt, B. G. 1993. How clonal are bacteria? Proc. Natl. Acad. Sci. U.S.A. 90:4384-4388.

Sommerhalder, R. J., McDonald, B. A., and Zhan, J. 2006. The frequencies and spatial distribution of mating types in Stagonospora nodorum are consistent with recurring sexual reproduction. Phytopathology 96:234-239.

Stoddart, J. A., and Taylor, J. F. 1988. Genotypic diversity: Estimation and prediction in samples. Genetics 118:705-711.

Teviotdale, B. L., Michailides, T. J., and Pscheidt, J. W., eds. 2002. Compendium of Nut Crop Diseases in Temperate Zones. American Phytopathological Society, St. Paul, MN, U.S.A.

Turgeon, B. G. 1998. Application of mating type gene technology to problems in fungal biology. Annu. Rev. Phytopathol. 36:115-137.

Turgeon, B. G., and Yoder, O. 2000. Proposed nomenclature for mating type genes of filamentous ascomycetes. Fungal Genet. Biol. 31:1-5.

Waalwijk, C., Mendes, O., Verstappen, E. C. P., de Waard, M. A., and Kema, G. H. J. 2002. Isolation and characterization of the mating type idiomorphs from the wheat Septoria leaf blotch fungus Mycosphaerella graminicola. Fungal Genet. Biol. 35:277-286.

Wang, N.-Y., Zhang, K., Huguet-Tapia, J. C., Rollins, J. A., and Dewdney, M. M. 2016. Mating type and simple sequence repeat markers indicate a 
clonal population of Phyllosticta citricarpa in Florida. Phytopathology 106: $1300-1310$.

Xu, X., Harvey, N., Roberts, A. L., and Barbara, D. J. 2013. Population variation of apple scab (Venturia inaequalis) within mixed orchards in the UK. Eur. J. Plant Pathol. 135:97-104.

Young, C. A., Bock, C. H., Charlton, N. D., Chakradhar, M., Krom, N., Bowen, J. K., Templeton, M., Plummer, K. M., and Wood, B. W. 2018. Evidence for sexual reproduction: Identification, frequency and spatial distribution of Venturia effusa (pecan scab) mating type idiomorphs. Phytopathology 108:837-846.

Yu, J.-J., Sun, W.-X., Yu, M.-N., Yin, X.-L., Meng, X.-K., Zhao, J., Huang, L., Huang, L., and Liu, Y.-F. 2015. Characterization of mating-type loci in rice false smut fungus Villosiclava virens. FEMS Microbiol. Lett. 36: fnv014. 